\title{
The Energy and Exergy of Light with Application to Societal Exergy Analysis
}

\author{
Matthew Kuperus Heun 1,*(D), Zeke Marshall 2 ${ }^{\mathbb{D}}$, Emmanuel Aramendia ${ }^{2}(\mathbb{D}$ \\ and Paul E. Brockway 2 (D) \\ 1 Department of Engineering, Calvin University, 3201 Burton St. SE, Grand Rapids, MI 49546, USA \\ 2 Sustainability Research Institute, School of Earth and Environment, University of Leeds, Leeds LS2 9JT, UK; \\ z.marshall@leeds.ac.uk (Z.M.); eeear@leeds.ac.uk (E.A.); p.e.brockway@leeds.ac.uk (P.E.B.) \\ * Correspondence: mkh2@calvin.edu; Tel.: +1-616-526-6663
}

Received: 20 August 2020; Accepted: 12 October 2020; Published: 20 October 2020

check for updates

\begin{abstract}
Lighting provides an indispensable energy service, illumination. The field of societal exergy analysis considers light (and many other energy products) to be enablers of economic growth, and lighting contributes a non-negligible proportion of total useful exergy supplied to modern economies. In societal exergy analysis, the exergetic efficiency of electric lamps is central to determining the exergy contribution of lighting to an economy. Conventionally, societal exergy practitioners estimate the exergetic efficiency of lamps by an energy efficiency, causing confusion and, sometimes, overestimation of exergetic efficiency by a factor as large as 3 . In response, we use recent results from the fields of radiation thermodynamics and photometry to develop an exact method for calculating the exergy of light and the exergetic efficiency of lamps. The exact method (a) is free of any assumptions for the value of the maximum luminous efficacy, (b) uses a non-unity spectral exergy-to-energy ratio, and (c) allows choices for the spectral luminous weighting function, which converts broad-spectrum electromagnetic radiation to light. The exact method exposes shortcomings inherent to the conventional method and leads to a reasonable approximation of lamp exergetic efficiency, when needed. To conclude, we provide three recommendations for societal exergy practitioners: use (a) the exact method when a lamp's spectral power distribution is available, (b) the universal luminous weighting function, and (c) the reasonable approximation to the exact method when a lamp's luminous efficacy is known but its spectral power distribution is not.
\end{abstract}

Keywords: exergy; efficiency; light; radiation; thermodynamics; illumination; lumen; luminous efficacy; spectrum

\section{Introduction}

\subsection{The Importance of Light and the Issue of Lighting Efficiency}

Lighting provides an indispensable energy service (illumination), enabling activities at times when natural light levels are insufficient. Illumination is so valuable that around $20 \%$ of global gridconnected electricity is consumed for the purpose of making artificial light [1]. With the breakthrough technology of light emitting diode (LED) lamps, which now comprise over $40 \%$ of lamp sales [2], applications of artificial lighting have spread beyond illumination to many other fields including human physiology and photosynthesis for horticulture [3]. Given the expanding role that artificial lighting plays globally, understanding precisely its potential contribution — via increasing efficiency-to reducing energy use to meet carbon dioxide emission targets is crucially important. Thus, the analysis of the energy and exergetic efficiency of lighting is important in many fields, including energy history [4], 
energy economics [5], ecological economics [6], forecasting energy efficiency improvements [2], and societal exergy analysis [7], the focus of this article.

\subsection{Lighting Fundamentals: Light Energy and the Energy Conversion Chain}

Ahead of a detailed treatment of the thermodynamics of light in Section 2.1, we set out here two fundamental aspects of lighting. The first aspect is clear definitions of electromagnetic (EM) energy and light. EM energy $(E$, in $\mathrm{J})$ is broad-spectrum EM radiation quantified by the energy of photons via Einstein's equation:

$$
E=h v=\frac{h c}{\lambda},
$$

where $h$ is Planck's constant $\left(6.626 \times 10^{-34} \mathrm{~J}-\mathrm{s}\right), v$ is frequency (in $\left.1 / \mathrm{s}\right), c$ is the speed of light $(\mathrm{in} \mathrm{m} / \mathrm{s})$, and $\lambda$ is wavelength (in $\mathrm{m}$ ). The human retina responds to a narrow wavelength range of EM radiation $(380 \mathrm{~nm}<\lambda<780 \mathrm{~nm}$ ). Thus, light is EM radiation within that narrow wavelength band [8], weighted by the eye's spectral (i.e., wavelength-specific) sensitivity (See Figure 1). We note that wavelengths of light are not inherently colored, but we have adopted the color representation of the Commission Internationale de l'Eclairage (CIE) 10 degree color matching function (CMF) [9], supplied by the $R$ package ggspectra [10], for demonstration purposes in Figure 1 and others. The figures show $555 \mathrm{~nm}$, the wavelength of the peak of the combined sensitivities of two of the human eyes' five light receptors, the long-wavelength $(\mathrm{L})$ and medium-wavelength $(\mathrm{M})$ cones.

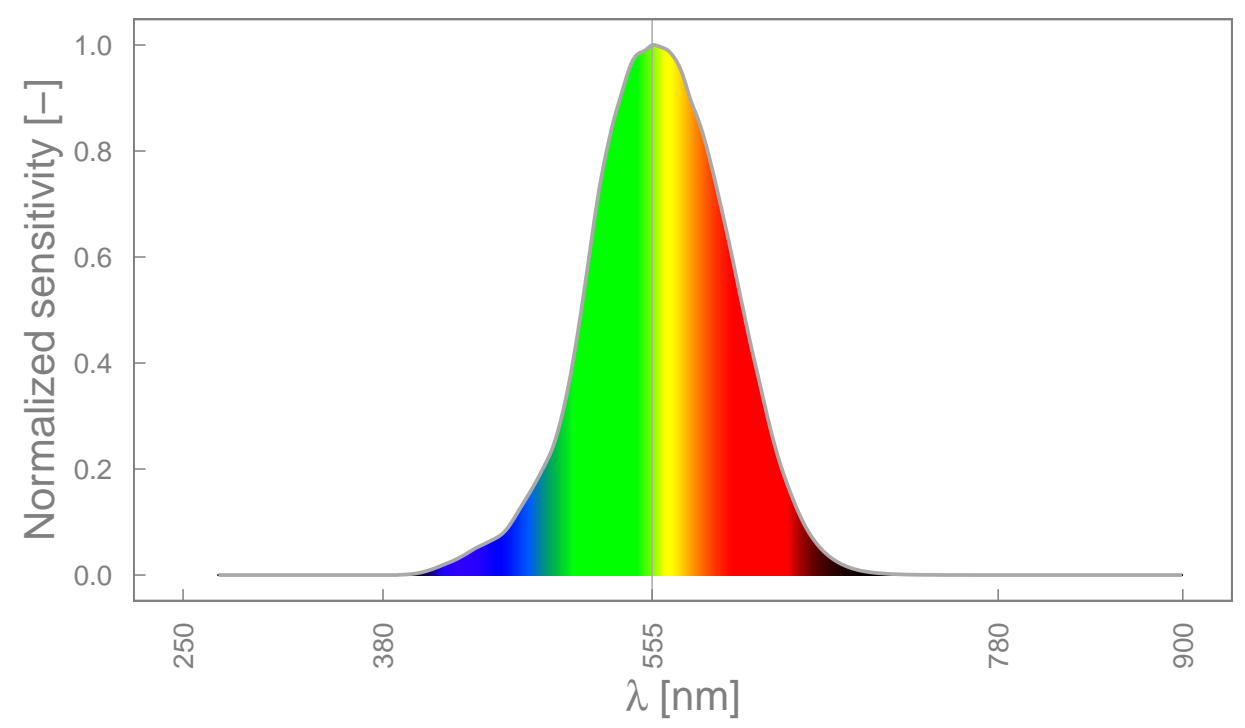

Figure 1. Normalized sensitivity and color perception of the human eye to EM radiation [11], according to the photopic luminous weighting function $\left(V_{\lambda}\right)$.

The second aspect is to note that modern lighting is provided via an energy conversion chain: primary energy carriers (e.g., coal) are converted to final energy (electricity, measured in watts, W) and lastly to useful energy (visible light, measured in lumens, $\mathrm{lm}$ ). The field of exergy analysis has long analyzed individual machines and power plants in the energy conversion chain for their exergetic efficiency and performance, e.g., co-generation power plants [12], nuclear power plants [13], refrigerators [14], heat pumps [15], and energy storage systems [16]. In contrast, the field of societal exergy analysis evaluates entire energy conversion chains at regional, national, or world levels in exergy terms and considers light (and many other useful energy products) to be enablers of economic growth. (Energy quantifies the potential to change temperature, whereas exergy quantifies the potential to do work). See Nakićenović et al. [17] for an early example and Guevara et al. [18], Heun and Brockway [19], and Ver Beek et al. [20] for later examples of societal exergy analysis. Thus, 
societal exergy analysis relies upon results from the energy and exergy analysis of lamps and lighting to assess the ways in which useful energy products enable economic growth.

Lighting contributes a non-negligible proportion of total useful exergy supplied to modern economies, so an essential metric in societal exergy analysis is the efficiency with which electricity (final stage) is converted to light (useful stage) by lamps. Therefore, the efficiency of energy and exergy conversion of electricity into light by electric lamps ( $\eta_{E}$ and $\eta_{X}$, respectively) is the focus of this article. Note that both energy services (e.g., illumination, the stage of the energy conversion chain termed "application efficacy" in photometry [21]) and satisfaction of human needs (e.g., comfort, safety, etc.) are downstream of the useful stage and thus beyond the scope of this paper.

\subsection{The Conventional Method and the Thorny Issue of Luminous Efficacy}

The valuable energy or exergy conversion efficiency $\left(\eta_{v}\right)$ is defined in simple terms as

$$
\eta_{v}=\frac{\text { valuable output }}{\text { input }}
$$

When the numerator and denominator are quantified in energy terms, an energy efficiency is obtained $\left(\eta_{E, v}\right)$. When the numerator and denominator are quantified in exergy terms, an exergetic efficiency is obtained $\left(\eta_{X, v}\right)$.

But light (the valuable output) is rarely quantified in energy terms and almost never in exergy terms. Instead, light is quantified in lumens (lm). Indeed, a common interpretation of Equation (2) uses light (in $1 \mathrm{~m}$ ) as the valuable output in the numerator and electricity (in $\mathrm{W}$ ) as the input in the denominator to obtain luminous efficacy $(K$, in $1 \mathrm{~m} / \mathrm{W})$. In fact, most lamps are rated and advertised by their lumen output and their luminous efficacy $(K)$. Figure 2 shows the evolution over time of luminous efficacy for four lamp technologies. (Data for Figure 2 were obtained from three sources: the Museum of Electric Lamp Technology (LampTech) [22], the ENERGYSTAR database of certified lamps [23], and the Lighting Market Characterization Reports commissioned by the US Department of Energy (DOE) [24-26]. See Supplementary Materials for additional information [27].)

Practitioners who use luminous efficacy as a lamp efficiency metric include Nordhaus [5] and Tsao and Waide, who state "[l]uminous efficacy represents the efficiency with which energy is used to produce visible light" [28] (p. 265).

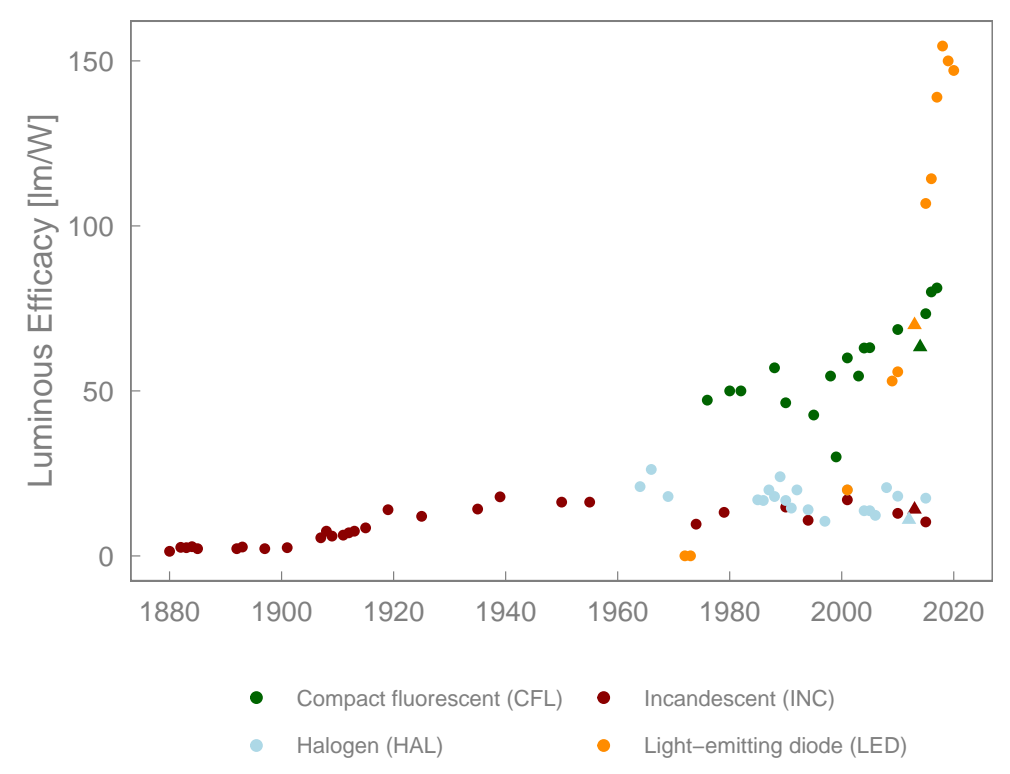

Figure 2. The luminous efficacy of selected lamp technologies from 1880 to 2020. Triangles indicate lamps used as examples in this paper. 
Sousa et al. note that societal exergy analysis is hampered when "the useful output cannot or is not typically measured in energy units" [29] (p. 17), as is the case with lighting. Indeed, societal exergy practitioners need the valuable energy and exergetic efficiencies of lamps $\left(\eta_{E, L, v}\right.$ and $\left.\eta_{X, L, v}\right)$, but lighting efficiencies are given in terms of luminous efficacy $(K)$. Thus, the widespread use of luminous efficacy $(K)$ as a measure of lamp efficiency provides a burden to societal exergy analysis.

Conventionally, societal exergy practitioners solve this problem by estimating the valuable $(v)$ exergetic $(X)$ efficiency $(\eta)$ of lighting $(L)$ by the ratio of the minimum energy required to produce a given output and the actual energy required to produce the same given output, as recommended by Sousa et al. [29] for sound, information, and lighting. (See Section 4.1.1 for additional detail). The conventional method is typically implemented for lighting via luminous efficacy with

$$
\eta_{X, L, v} \approx \frac{K}{K_{\max }}
$$

where $K$ is the actual lamp luminous efficacy and $K_{\max }$ is the theoretical maximum luminous efficacy.

However, Equation (3) exposes a source of confusion, namely what value should be used for $K_{\max }$ ? Within the societal exergy analysis literature and beyond, three common values are adopted: $220 \mathrm{~lm} / \mathrm{W}$ [30-32], $400 \mathrm{~lm} / \mathrm{W}$ [7,18,30,33], and $683 \mathrm{~lm} / \mathrm{W}$ [34,35]. To our knowledge, the earliest reference for $220 \mathrm{~lm} / \mathrm{W}$ and $400 \mathrm{~lm} / \mathrm{W}$ is Summers [30] (p. 151), who stated "[t]he efficiencies ... assume that the maximum attainable efficiency for an acceptable white light is about 400 lumens per watt rather than the theoretical value of 220 lumens per watt for a perfectly 'flat' white light". The value of $683 \mathrm{~lm} / \mathrm{W}$ is derived from the definition of the lumen. It represents the luminous efficacy of a lamp emitting light at $555 \mathrm{~nm}$, the peak of the photopic luminous weighting function, with electricity converted EM radiation at $100 \%$ efficiency.

Paoli and Cullen estimated the practical upper limit for the luminous efficacy of an LED lamp to be $284-350 \mathrm{~lm} / \mathrm{W}$, when considering all sources of energy loss (driver efficiency, wall plug efficiency, optical efficiency, and spectral efficiency) [36]. The development of LED technology is following Haitz's law, which predicts that "[e]very decade, for a given wavelength of light, the cost per lumen falls by a factor of 10 and the amount of light generated per LED package increases by a factor of 20 " $[37,38]$. Figure 2 shows that LED technology is nearing the lower efficacies from Summers $(220 \mathrm{~lm} / \mathrm{W})$ and Paoli and Cullen $(284 \mathrm{~lm} / \mathrm{W})$.

Clearly, there are many options for $K_{\max }$, and its value has a large effect on the valuable exergetic efficiency of lighting in the conventional method (Equation (3)). So getting it right is important.

\subsection{Need, Aim, Contributions, and Structure}

Although the confusion around maximum luminous efficacy $\left(K_{\max }\right)$ is sufficient motivation to dig deeper to fully understand and define the exergy of light and the exergetic efficiency of lamps, further issues and confusions await. (See Section 4). Thus, there is ample need for clarity and rigor about the thermodynamics of artificial lighting.

The need leads to the aim of this article: to bring clarity to (a) the energy and exergy of light and (b) the valuable energy and exergetic efficiency of lamps for societal exergy analysis.

The novel contributions of this article include: (a) clear and rigorous definitions of the energy and exergy of light, applicable to the field of societal exergy analysis (Section 2.1.4), (b) presentation of a framework for understanding the exergetic efficiency of lamps (the exact method, Section 2.1.5), (c) application of the exact method to re-interpret the conventional method, exposing its shortcomings (Section 4.1.1), (d) recommendations for societal exergy analysis going forward (Section 4.2), and (e) development of an approximate method for cases when an approximation to the exact method is needed (Section 4.2.3).

The structure of this article is as follows: In Section 2, we (a) set out the energy and exergy fundamentals of light and lighting efficiency and (b) define luminous weighting functions and spectral power distributions for example lamps. In Section 3, we show results for luminous weighting functions 
and example lamps before presenting a discussion in Section 4 . Section 5 summarizes and suggest future work.

\section{Methods}

\subsection{Exergy Theory}

Energy and exergy are two ways to quantify the physical property that, when transferred to an object, changes its temperature or performs work on it. (In this section, we can't call the "physical property" energy, exergy, work, or heat, because these concepts must remain apart, so we use the generic term "physical property"). We discuss energy and exergy quantifications of the physical property in the sections below, beginning with heat and work, the concepts for which energy and exergy originated. Thereafter, we develop a framework for the energy and exergy of light that parallels the energy and exergy of heat and work.

\subsubsection{Energy and Exergy ( $\dot{E}$ and $\dot{X})$ of Heat and Work}

Energy quantifies the physical property by its heat content. Thus, heat (the ability to influence temperature) is pure energy. Thanks to Thompson's cannon experiment [39], we know that work can be converted into heat without loss.

Figure 3 shows a heat engine that converts heat at (1) to work at (3) with a waste heat byproduct at (2). All streams can be counted as energy $(\dot{E})$, such that

$$
\begin{aligned}
& \dot{E}_{1}=\dot{Q}_{1}, \\
& \dot{E}_{2}=\dot{Q}_{2}, \text { and } \\
& \dot{E}_{3}=\dot{W}_{3} .
\end{aligned}
$$

Note that the overdot notation, as in $\dot{E}, \dot{Q}$, and $\dot{W}$, indicates a steady state rate of energy or exergy flow.

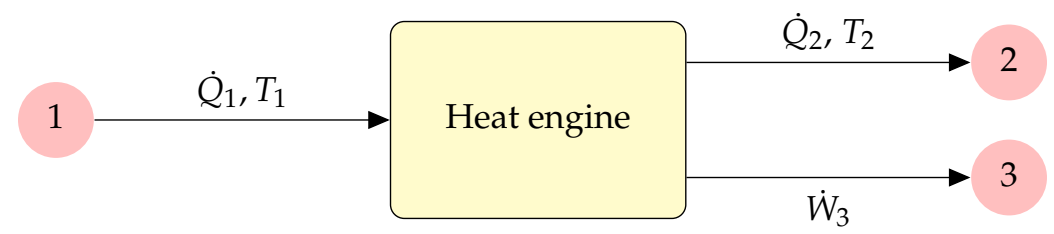

Figure 3. A heat engine that uses heat at (1) to produce heat at (2) and work at (3).

Energy efficiency is defined as $\eta_{E} \equiv \frac{\text { energy out }}{\text { energy in }}$. For the example of Figure 3,

$$
\eta_{E}=\frac{\dot{E}_{2}+\dot{E}_{3}}{\dot{E}_{1}}=\frac{\dot{Q}_{2}+\dot{W}_{3}}{\dot{Q}_{1}}=1
$$

because the first law of thermodynamics requires that energy is conserved $\left(\dot{Q}_{1}=\dot{Q}_{2}+\dot{W}_{3}\right)$.

That said, typically only one of the products in Figure 3 is deemed valuable: the work produced by the heat engine $\left(\dot{W}_{3}\right)$. Thus, the valuable energy efficiency $\left(\eta_{E, v}\right)$ is

$$
\eta_{E, v}=\frac{\dot{E}_{3}}{\dot{E}_{1}}=\frac{\dot{W}_{3}}{\dot{Q}_{1}}<1
$$

Heat (the ability to influence temperature) is only one possible outcome of transferring the physical property from one object to another. Heat is certainly valuable to humans, but so is another property: work, the ability to exert a force on another object. Exergy quantifies the physical property by its work potential and provides the answer to the question "what is the maximum work we could obtain from a stream of the physical property"? Thus, work is pure exergy. 
The Kelvin-Planck statement of the second law of thermodynamics states that heat cannot be converted to work without loss. To find the maximum possible work that can be created from heat (and, therefore, the exergy of heat), we require the Carnot heat engine, which operates at the maximum possible valuable energy efficiency $\left(\eta_{C}\right)$.

$$
\eta_{C}=1-\frac{T_{0}}{T_{s y s}}
$$

$T_{0}$ is the ambient temperature, and $T_{\text {sys }}$ is a heat temperature $\left(T_{1}\right.$ or $T_{2}$ in Figure 3$)$. The exergy of each stream in Figure 3 is then

$$
\begin{aligned}
& \dot{X}_{1}=\phi_{1} \dot{Q}_{1}=\left(1-\frac{T_{0}}{T_{1}}\right) \dot{Q}_{1}, \\
& \dot{X}_{2}=\phi_{2} \dot{Q}_{2}=\left(1-\frac{T_{0}}{T_{2}}\right) \dot{Q}_{2}, \text { and } \\
& \dot{X}_{3}=\phi_{3}^{1} \dot{W}_{3}=\dot{W}_{3} .
\end{aligned}
$$

In this context, the Carnot efficiency $\left(\eta_{C}\right)$ becomes the exergy-to-energy ratio for heat streams $\left(\phi_{Q}=\eta_{C}\right)$. The exergy-to-energy ratio for work is $\phi_{3}=\phi_{W}=1$, because work is pure exergy. (The exergyto-energy ratio, $\phi$, is exergy divided by energy at a statepoint. E.g., $\left.\phi_{1}=\dot{X}_{1} / \dot{E}_{1}\right)$.

The exergetic efficiency of an energy conversion device is defined as $\eta_{X} \equiv \frac{\text { exergy out }}{\text { exergy in }}$. For the heat engine in Figure 3,

$$
\eta_{X}=\frac{\dot{X}_{2}+\dot{X}_{3}}{\dot{X}_{1}}=\frac{\dot{Q}_{2}\left(1-\frac{T_{0}}{T_{2}}\right)+\dot{W}_{3}}{\dot{Q}_{1}\left(1-\frac{T_{0}}{T_{1}}\right)}<1,
$$

because all real processes are internally irreversible, such that $\dot{X}_{1}>\dot{X}_{2}+\dot{X}_{3}$ or $\dot{X}_{D}=\dot{X}_{1}-\left(\dot{X}_{2}+\dot{X}_{3}\right)$.

Assuming, again, that work is the valuable output gives

$$
\eta_{X, v}=\frac{\dot{W}_{3}}{\dot{Q}_{1}\left(1-\frac{T_{0}}{T_{1}}\right)}<\eta_{X}<1 .
$$

Note that both $\eta_{E, v}$ and $\eta_{X, v}$ are independent of human presence. The work created by the heat engine $\left(\dot{W}_{3}\right)$ could be a spinning driveshaft on an automobile carrying four passengers down the freeway or the same spinning driveshaft on a dynamometer in an unoccupied laboratory. Both (a) the energy and exergy of the work and heat at (2) and (3) and (b) the energy and exergy efficiencies of the heat engine $\left(\eta_{E, v}\right.$ and $\left.\eta_{X, v}\right)$ would be the same, regardless. In other words, both (a) the energy and exergy of work and heat and (b) the efficiencies of the heat engine are independent of human presence and the energy service provided by the heat engine.

We now turn from the production of work by a heat engine to the production of light by a lamp.

\subsubsection{Energy and Exergy of EM Radiation ( $\dot{E}_{E M}$ and $\left.\dot{X}_{E M}\right)$}

Figure 4 replaces the heat engine with a lamp that produces broad-spectrum EM radiation $\left(\dot{E}_{E M, 3}\right)$ instead of work $\left(\dot{W}_{3}\right)$. Electricity powers the lamp at (1), and, like Figure 3, waste heat (conduction and convection only) is produced at (2).

Both electricity and EM radiation can be converted to heat without loss, so they are pure energy. Thus,

$$
\begin{aligned}
& \dot{E}_{1}=\dot{W}_{\text {elect }, 1}, \\
& \dot{E}_{2}=\dot{Q}_{2}, \text { and } \\
& \dot{E}_{3}=\dot{E}_{E M, 3},
\end{aligned}
$$


where $\dot{E}_{E M, 3}$ is the radiant power of broad-spectrum EM radiation emitted by the lamp in units of energy per unit time $(\mathrm{W})$. (Confusingly, radiant power is sometimes called "radiant flux" in the literature, despite the fact that radiant power is in units of $W$, whereas flux would be in units of $W / \mathrm{m}^{2}$. When exergy is not involved, the photometry literature often denotes radiant power by $\Phi$, not $\dot{E}$. Here, we need to differentiate between the energy rate of broad spectrum EM radiation $\left(\dot{E}_{E M}\right)$ and the exergy rate of broad spectrum EM radiation $\left(\dot{X}_{E M}\right)$, so we reserve $\Phi$ for lumen output of a lamp. See Section 2.2.1).

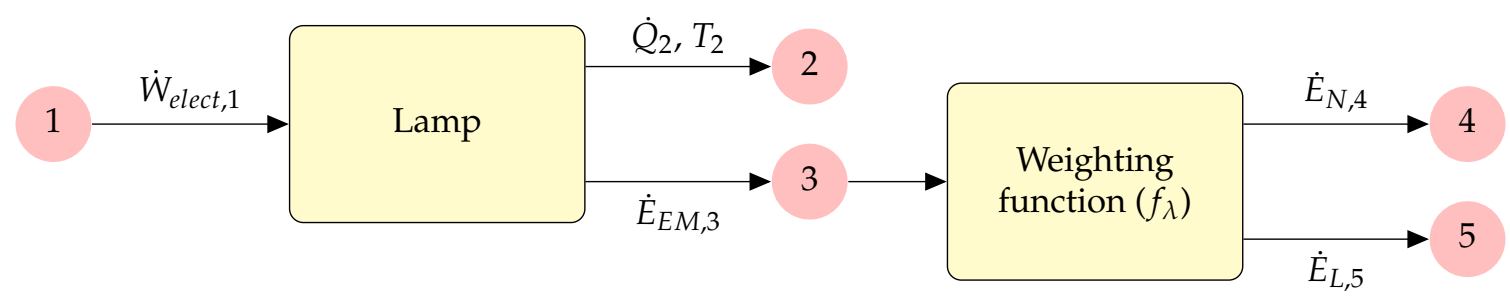

Figure 4. A lamp that uses electricity at (1) to produce heat at (2), broad-spectrum EM radiation at (3), non-light EM radiation at (4), and light at (5).

The lamp's energy efficiency $\left(\eta_{E, E M}\right)$ is

$$
\eta_{E, E M}=\frac{\dot{E}_{2}+\dot{E}_{3}}{\dot{E}_{1}}=\frac{\dot{Q}_{2}+\dot{E}_{E M, 3}}{\dot{W}_{\text {elect }, 1}}=1
$$

The valuable energy efficiency of the lamp in Figure $4\left(\eta_{E, E M, v}\right.$, also called the wall plug efficiency) is

$$
\eta_{E, E M, v}=\frac{\dot{E}_{3}}{\dot{E}_{1}}=\frac{\dot{E}_{E M, 3}}{\dot{W}_{\text {elect }, 1}}<1,
$$

assuming that broad-spectrum EM radiation at (3) is the valuable output from the lamp.

Because electricity can be converted to work without loss in a frictionless motor, electricity is considered pure exergy, i.e., $\phi_{\text {elect }}=1$. Thus, the exergy of the first three streams in Figure 4 is given by

$$
\begin{aligned}
& \dot{X}_{1}=\phi_{\text {elect }}{ }^{1} \dot{W}_{\text {elect }, 1}=\dot{W}_{\text {elect }, 1}, \\
& \dot{X}_{2}=\left(1-\frac{T_{0}}{T_{2}}\right) \dot{Q}_{2}, \text { and } \\
& \dot{X}_{3}=\phi_{E M} \dot{E}_{E M, 3},
\end{aligned}
$$

where $\phi_{E M}$ is the exergy-to-energy ratio for broad-spectrum EM radiation. (See Section 2.1.4 for details).

In general, the radiant power of a lamp is a spectral quantity, meaning that it varies with wavelength. Spectral radiant power $\left(\dot{E}_{E M, \lambda}\right)$ is the EM emissive power available between any two wavelengths and is related to radiant power $\left(\dot{E}_{E M}\right)$ by

$$
\dot{E}_{E M}=\int \dot{E}_{E M, \lambda} \mathrm{d} \lambda
$$

(See Benenson et al. [40].) Visually, $\dot{E}_{E M}$ is the area under the $\dot{E}_{E M, \lambda}$ vs. $\lambda$ curve.

The exergetic efficiency of EM radiation emitted by the lamp in Figure 4 is given by

$$
\eta_{X, E M}=\frac{\dot{X}_{2}+\dot{X}_{3}}{\dot{X}_{1}}=\frac{\left(1-\frac{T_{0}}{T_{2}}\right) \dot{Q}_{2}+\phi_{E M} \dot{E}_{E M, 3}}{\dot{W}_{\text {elect }, 1}}<1,
$$


In general, $\phi_{E M}$ is also a spectral quantity. (See Section 2.1.4). The valuable exergetic efficiency of the EM radiation emitted by the lamp in Figure 4 is given by

$$
\eta_{X, E M, v}=\frac{\dot{X}_{3}}{\dot{X}_{1}}=\frac{\phi_{E M} \dot{E}_{E M, 3}}{\dot{W}_{\text {elect }, 1}}<\eta_{X, E M}<1 .
$$

Note that the efficiencies are independent of human presence; $\eta_{X, E M}$ and $\eta_{X, E M, v}$ would be the same, whether the lamp is illuminating an unoccupied room or a crowded bar, or whether the illumination stimulates the rods and cones of a human eye or excites band gap electrons in an amorphous silicon solar cell.

\subsubsection{Energy and Exergy of Light $\left(\dot{E}_{L}\right.$ and $\left.\dot{X}_{L}\right)$}

We noted above that both (a) energy and exergy of broad-spectrum EM radiation and (b) EM energy and exergetic efficiency of lamps are independent of human presence. But what about human perception?

Human beings perceive conductive and convective heat by temperature and EM radiation by wavelength. Human skin can perceive the thermal radiation portion of the broader electromagnetic spectrum, approximately $100 \mathrm{~nm}<\lambda<10,000 \mathrm{~nm}$, and human skin is differentially responsive to EM wavelength [41]. Indeed, thermoreceptors in the dermis of skin are important sensors for regulation of body temperature [42] (p. 258). Similarly, human eyes perceive only a (narrower) portion of the EM radiation spectrum (approximately $380 \mathrm{~nm}<\lambda<780 \mathrm{~nm}$ ). To quantify the energy (and exergy) of light, we must move from the energy and exergy of broad-spectrum EM radiation ( $\dot{E}_{E M}$ and $\dot{X}_{E M}$ ) to the energy and exergy of light $\left(\dot{E}_{L}\right.$ and $\left.\dot{X}_{L}\right)$. But how?

Knowing that visual perception of light is a function of wavelength leads to modifying Equation (23) to include a spectral luminous weighting function $\left(f_{\lambda}\right)$ such that

$$
\dot{E}_{L}=\int \dot{E}_{L, \lambda} \mathrm{d} \lambda=\int f_{\lambda} \dot{E}_{E M, \lambda} \mathrm{d} \lambda,
$$

with $0 \leq f_{\lambda} \leq 1$ and $\dot{E}_{L, \lambda}=f_{\lambda} \dot{E}_{E M, \lambda}$.

In Equation (26), the spectral luminous weighting function $\left(f_{\lambda}\right)$ converts broad-spectrum EM radiation $\left(\dot{E}_{E M}\right.$ and $\left.\dot{X}_{E M}\right)$ to light $\left(\dot{E}_{L}\right.$ and $\left.\dot{X}_{L}\right)$, the valuable part of EM radiation for illumination. In the context of Figure 4,

$$
\dot{E}_{L, 5}=\int f_{\lambda} \dot{E}_{E M, \lambda, 3} \mathrm{~d} \lambda \text {. }
$$

In Figure 4, any EM radiation at statepoint 3 not converted to light is quantified as non-light EM radiation at statepoint $4\left(\dot{E}_{N, 4}\right)$. Specifically,

$$
\dot{E}_{N, 4}=\int\left(1-f_{\lambda}\right) \dot{E}_{E M, \lambda, 3} \mathrm{~d} \lambda .
$$

\subsubsection{The Exergy-To-Energy Ratio of EM Radiation $\left(\phi_{E M}\right)$}

Recent advances in the thermodynamics of radiation community enable converting the energy of EM radiation $\left(\dot{E}_{E M}\right)$ into the exergy of EM radiation $\left(\dot{X}_{E M}\right)$ [43]. The exergy-to-energy ratio of EM radiation ( $\phi_{E M}$, called the "radiative exergy-energy coefficient" in that community) is most commonly given by Petela's Equation [43-45]:

$$
\phi_{E M}=1-\frac{4}{3} \frac{T_{0}}{T_{1}}+\frac{1}{3}\left(\frac{T_{0}}{T_{1}}\right)^{4},
$$

where $T_{1}$ is the temperature of a blackbody emitter and $T_{0}$ is the temperature of a blackbody absorber. Petela's equation has recently been verified via an infinite-staged Carnot heat engine model [46] that is powered by radiative energy transfer. In the radiative Carnot model, a photon possessing a characteristic frequency and photon effective temperature enters a medium that acts as an ideal 
absorber. The photon transfers an infinitesimal quantity of energy to the absorber via thermal radiation. The energy enters an infinitesimally small Carnot heat engine and performs work. The absorber then emits another photon at lower energy and frequency, and therefore lower photon effective temperature. This process repeats until the frequency of the photon is zero and the photon effective temperature $\left(T_{\lambda}\right)$ equals the reference temperature $\left(T_{0}\right)$ [43].

However, Petela's equation assumes a blackbody emitter (at $\left.T_{1}\right)$ and a blackbody absorber (at $\left.T_{0}\right)$. To determine $\phi_{E M}$ for an emitter that is a non-blackbody lamp, the spectral exergy-to-energy ratio $\left(\phi_{E M, \lambda}\right)$, must be calculated. Recently, Delgado-Bonal was the first to quantify the spectral entropy of radiation, which reduces to Petela's equation when the full spectrum is considered [45]. Here, we use an effective temperature of light photons [47] $\left(T_{\lambda}\right)$ to obtain the link between Petela's equation (Equation (29)) and the spectral exergy-to-energy ratio $\left(\phi_{E M, \lambda}\right)$. The product of wavelength and photon effective temperature is a constant ( $c_{3}$ in Chen et al. [47]) such that

$$
\lambda T_{\lambda}=c_{3}=5.33016 \times 10^{-3} \mathrm{~m}-\mathrm{K},
$$

or

$$
T_{\lambda}=\frac{c_{3}}{\lambda}=\frac{5.33016 \times 10^{-3} \mathrm{~m}-\mathrm{K}}{\lambda} .
$$

We note that the photon effective temperature approach has been criticized by Liu, who argued that it is inappropriate "to endue a single photon with macro-scale thermodynamic parameters such as exergy and entropy" [48] (p. 1810). We acknowledge this critique, but we also note that here $T_{\lambda}$ is ascribed to a stream of photons traveling from a lamp to an eye. Thus, for our purposes, $T_{\lambda}$ can be considered the statistical average effective temperature of that stream of photons, in accordance with Shan and Zhou [43].

We assume that the mechanism by which light is converted into electrical nerve signals in the human eye is radiative EM energy transfer from a light source (1) to an eye (0). We assume no losses in radiative transmission between the lamp and the iris, i.e., no radiation scattering occurs through air, an assumption that holds for short distances typically observed in lighting applications $(<10 \mathrm{~m})$. (See Shan and Zhou [43] for a method to estimate transmission losses over longer distances). We further assume that the human iris is a blackbody absorber (absorbing all wavelengths of radiation perfectly [40]), being a small aperture on a larger cavity. (In this assumption, we follow Rossing and Chiaverina [49] (p. 172) who state "another good example of [a blackbody absorber] is the human eye; the pupil looks black because most light entering it is trapped and absorbed"). Thus, we use Shan and Zhou's [43] spectral formulation of Petela's equation, which replaces the temperature of the emitter $\left(T_{1}\right)$ by photon effective temperature $\left(T_{\lambda}\right)$ :

$$
\phi_{E M, \lambda}=1-\frac{4}{3}\left(\frac{T_{0}}{T_{\lambda}}\right)+\frac{1}{3}\left(\frac{T_{0}}{T_{\lambda}}\right)^{4} .
$$

Further, Equation (31) (in the form $T_{\lambda}=c_{3} / \lambda$ ) can be substituted into Equation (32), and $T_{0}$ can be taken as $310 \mathrm{~K}$, the temperature of the human body. The result is an equation for $\phi_{L, \lambda}$, the spectral exergy-to-energy ratio of light:

$$
\phi_{L, \lambda}=1-\frac{4}{3}\left(\frac{310 \mathrm{~K}}{c_{3}}\right) \lambda+\frac{1}{3}\left(\frac{310 \mathrm{~K}}{c_{3}}\right)^{4} \lambda^{4} .
$$

The exergy of light emitted by a non-blackbody lamp $\left(\dot{X}_{L}\right)$ is found by integrating the product of the spectral radiant power $\left(\dot{E}_{E M, \lambda}\right)$, a spectral luminous weighting function $\left(f_{\lambda}\right)$, and the spectral exergy-to-energy ratio $\left(\phi_{L, \lambda}\right)$ with respect to wavelength.

$$
\dot{X}_{L}=\int \phi_{L, \lambda} f_{\lambda} \dot{E}_{E M, \lambda} \mathrm{d} \lambda
$$


The quotient of $\dot{X}_{L}$ and $\dot{E}_{L}$ gives the exergy-energy ratio of light $\left(\phi_{L}\right)$, which is specific to each combination of weighting function and lamp $\left(f_{\lambda} \dot{E}_{E M, \lambda}\right)$.

$$
\phi_{L}=\frac{\dot{X}_{L}}{\dot{E}_{L}}=\frac{\int \phi_{L, \lambda} f_{\lambda} \dot{E}_{E M, \lambda} \mathrm{d} \lambda}{\int f_{\lambda} \dot{E}_{E M, \lambda} \mathrm{d} \lambda}
$$

Table 1 summarizes the key equations in Sections 2.1.1-2.1.4.

Table 1. Summary of equations for energy and exergy of work, electricity, heat, EM radiation, and light. $T_{0}$ is the environment temperature, $T_{1}$ is the temperature of heat, and $T_{\lambda}$ is the photon effective temperature (Equation (31)). Note that $\dot{X}=\phi \dot{E}$ on a spectral basis, if needed.

\begin{tabular}{cccc}
\hline Quantity & Energy Rate $(\dot{E})$ & Exergy-To-Energy Ratio $(\phi)$ & Exergy Rate $(\dot{X})$ \\
\hline Work & $\dot{E}_{W}=\dot{W}$ & $\phi_{W}=1$ & $\dot{X}_{W}=\dot{W}$ \\
Electricity & $\dot{E}_{\text {elect }}=\dot{W}_{\text {elect }}$ & $\phi_{\text {elect }}=1$ & $\dot{X}_{\text {elect }}=\dot{W}_{\text {elect }}$ \\
Heat & $\dot{E}_{Q}=\dot{Q}$ & $\phi_{Q}=1-\frac{T_{0}}{T_{1}}$ & $\dot{X}_{Q}=\left(1-\frac{T_{0}}{T_{1}}\right) \dot{Q}$ \\
EM rad. & $\dot{E}_{E M}=\int \dot{E}_{E M, \lambda} \mathrm{d} \lambda$ & $\phi_{E M, \lambda}=1-\frac{4}{3} T_{0}+\frac{1}{3}\left(\frac{T_{0}}{T_{\lambda}}\right)^{4}$ & $\dot{X}_{E M}=\int \phi_{E M, \lambda} \dot{E}_{\lambda} \mathrm{d} \lambda$ \\
Light & $\dot{E}_{L}=\int f_{\lambda} \dot{E}_{E M, \lambda} \mathrm{d} \lambda$ & $\phi_{L, \lambda}=1-\frac{4}{3}\left(\frac{310 \mathrm{~K}}{c_{3}}\right) \lambda+\frac{1}{3}\left(\frac{310 \mathrm{~K}}{c_{3}}\right)^{4} \lambda^{4}$ & $\dot{X}_{L}=\int \phi_{L, \lambda} f_{\lambda} \dot{E}_{E M, \lambda} \mathrm{d} \lambda$ \\
\hline
\end{tabular}

\subsubsection{Lighting Efficiency of a Lamp}

If the valuable product of a lamp is considered to be its light $\left(\dot{E}_{L}\right.$ or $\left.\dot{X}_{L}\right)$ as opposed to its broadspectrum EM radiation $\left(\dot{E}_{E M}\right.$ or $\left.\dot{X}_{E M}\right)$, Equations (19) and (25) require modification. In the context of Figure 4 , the valuable energy efficiency of a lamp becomes

$$
\eta_{E, L, v}=\frac{\dot{E}_{5}}{\dot{E}_{\text {elect }, 1}}=\frac{\int f_{\lambda} \dot{E}_{E M, \lambda, 3} \mathrm{~d} \lambda}{\dot{W}_{\text {elect }, 1}},
$$

and the valuable exergetic efficiency of a lamp becomes

$$
\eta_{X, L, v}=\frac{\dot{X}_{5}}{\dot{X}_{\text {elect }, 1}}=\frac{\int \phi_{L, \lambda} f_{\lambda} \dot{E}_{E M, \lambda, 3} \mathrm{~d} \lambda}{\dot{W}_{\text {elect }, 1}}
$$

\subsection{Examples and Data}

\subsubsection{Luminous Weighting Functions}

Spectral luminous weighting functions $\left(f_{\lambda}\right)$ convert radiant power $\left(\dot{E}_{E M}\right.$ and $\left.\dot{X}_{E M}\right)$ to light $\left(\dot{E}_{L}\right.$ and $\dot{X}_{L}$ ). (See Section 2.1.3). We use four spectral luminous weighting functions relevant to illumination to enable example calculations. (See Section 3).

The first luminous weighting function option is degenerate: the practitioner could decide to ignore the nuances of human visual perception altogether, implicitly assuming that all EM radiation emitted from a lamp counts as light, whether or not it is within the visible portion of the EM spectrum. For the first option, the degenerate (unweighted, uw) luminous weighting function $\left(f_{\lambda, u w}\right)$ is

$$
f_{\lambda, u w}=1 .
$$

Second, the practitioner could deem a lamp's EM radiation to be useful if and only if it could stimulate photoreceptive cells in the human eye, regardless of the spectral sensitivity of those cells. 
In the second option, the practitioner excludes wavelengths outside the range of perception by the human eye when determining the energy or exergy of light. For the second option (visible, vis),

$$
f_{\lambda, v i s}= \begin{cases}0, & \text { for } \lambda<380 \mathrm{~nm} \\ 1, & \text { for } 380 \mathrm{~nm} \leq \lambda \leq 780 \mathrm{~nm} \\ 0, & \text { for } 780 \mathrm{~nm}<\lambda .\end{cases}
$$

But the human eye is spectrally sensitive to EM radiation, with peak sensitivity at $555 \mathrm{~nm}$ and lesser sensitivities at both longer (redder, $\lambda>\sim 620 \mathrm{~nm}$ ) and shorter (bluer, $\lambda<\sim 450 \mathrm{~nm}$ ) wavelengths. A third option weights a lamp's emitted EM radiation by the photopic sensitivity of the human eye. The photopic luminous ( $\mathrm{pl}$ ) weighting function $\left(V_{\lambda}\right)$ describes this sensitivity, as shown in Figure 1. The photopic luminous weighting function was defined by the Commission Internationale de l'Eclairage (CIE) in 1931 and represents the sensitivity of M and L cones at daytime light levels [50]. So for option 3,

$$
f_{\lambda, p l}=V_{\lambda} .
$$

Substituting Equation (40) into Equation (26) yields

$$
\dot{E}_{L, p l}=\int V_{\lambda} \dot{E}_{E M, \lambda} \mathrm{d} \lambda
$$

which provides the basis for calculating a lamp's output of visible light $\left(\Phi_{p l}\right)$ in the unit of lumens $(1 \mathrm{~m})$ :

$$
\Phi_{p l} \equiv(683 \mathrm{~lm} / \mathrm{W}) \dot{E}_{L, p l}=(683 \mathrm{~lm} / \mathrm{W}) \int V_{\lambda} \dot{E}_{E M, \lambda} \mathrm{d} \lambda,
$$

where $683 \mathrm{~lm} / \mathrm{W}$ is the luminous efficacy of a perfect light source emitting light at $\lambda=555 \mathrm{~nm}$. (Note that because lumens are a re-scaling of watts, lumens are also a unit of radiant power, thus $\Phi_{p l}$ is sometimes called luminous power. Unfortunately, similar to how radiant power is sometimes called "radiant flux," luminous power is sometimes erroneously called "luminous flux").

When the photopic luminous weighting function $\left(V_{\lambda}\right)$ is used to calculate radiant power, the valuable energy efficiency of a lamp can be written in terms of luminous efficacy $(K)$ by modifying Equation (36) to be (in the context of Figure 4)

$$
K \equiv \frac{(683 \mathrm{~lm} / \mathrm{W}) \int V_{\lambda} \dot{E}_{E M, \lambda, 3} \mathrm{~d} \lambda}{\dot{W}_{\text {elect }, 1}}
$$

where $K$ is in $1 \mathrm{~m} /$ watt.

The photopic luminous weighting function $\left(V_{\lambda}\right)$ is the industry standard for determining lumen output of lamps, but it has been criticized for under-representing the power of wavelengths different from $555 \mathrm{~nm}$. In fact, the photopic luminous weighting function neglects the sensitivity of the human eye's other light receptors, namely the short-wave cones, rods, and intrinsically photosensitive retinal ganglion cells (ipRGCs), which are responsible for vision in low-light settings and physiological functions such as the regulation of circadian rhythms. Thus, the photopic luminous weighting function $\left(V_{\lambda}\right)$, and therefore also luminous efficacy $(K)$, are said to have a long-wave bias.

A fourth option (universal, univ) weights a lamp's spectral radiant power $\left(\dot{E}_{E M, \lambda}\right.$ and $\left.\dot{X}_{E M, \lambda}\right)$ by the spectral sensitivity of all five light receptors in the human eye (not just the $\mathrm{M}$ and $\mathrm{L}$ cones as does $\left.V_{\lambda}\right)$. The universal luminous weighting function $\left(U_{\lambda}\right)$ [51] captures the actual, broader sensitivity of the human eye. So for option 4 ,

$$
f_{\lambda, \text { univ }}=U_{\lambda}
$$

Table 2 summarizes the luminous weighting functions discussed above. 
Table 2. Weighting functions.

\begin{tabular}{cc}
\hline Weighting Function & Effect \\
\hline Unweighted $\left(f_{\lambda, u w}=1\right)$ & None \\
Visible $\left(f_{\lambda, v i s}=1\right.$ in visible wavelengths only $)$ & Restricts to $380 \mathrm{~nm}<\lambda<780 \mathrm{~nm}$ \\
Photopic luminsosity $\left(f_{\lambda, p l}=V_{\lambda}\right)[50]$ & Accounts for the sensitivity of medium and long cones \\
Universal luminosity $\left(f_{\lambda, u n i v}=U_{\lambda}\right)[51]$ & Accounts for the sensitivity of all light receptors \\
\hline
\end{tabular}

To demonstrate how the spectral luminous weighting function $\left(f_{\lambda}\right)$ affects the energy and exergetic efficiency of lamps, we need both luminous weighting functions and example lamps, the topic of the next section.

\subsubsection{Lamps}

We obtained spectral power distributions (SPDs) of the lamps in Table 3 from the Light Spectral Power Distribution Database (LSPDD) [52-54]. In the LSPDD, lamp spectral power distributions (SPDs) are available in the range of $250 \mathrm{~nm}<\lambda<900 \mathrm{~nm}$, and data are provided in terms of relative intensity $\left(\dot{E}_{E M, \lambda, \text { rel }}\right)$ as opposed to absolute intensity $\left(\dot{E}_{E M, \lambda}\right)$. Because lamps in the LSPDD are not measured using an integrating sphere, the integral of the SPD may not match the radiant power of the lamp reported by the manufacturer. To ensure that the integral of each lamp's SPD matches its reported radiant power, we applied the standard procedure of scaling the SPD by the ratio $(\mu)$ of the radiant power given by the manufacturer $\left(K \dot{W}_{\text {elect }, 1}\right)$ to the integral of the spectral radiant power taken from the relative intensity data $\left(\dot{E}_{E M, \lambda, r e l}\right)$.

$$
\mu \equiv \frac{K \dot{W}_{\text {elect }, 1}}{\dot{E}_{E M, r e l}} .
$$

We then applied the scaling factor $(\mu)$ to the SPD for each lamp, yielding a corrected SPD $\left(\dot{E}_{E M, \lambda}\right)$ that matches the manufacturer's reported radiant power.

$$
\dot{E}_{E M, \lambda}=\mu \dot{E}_{E M, \lambda, r e l}
$$

Although corrected SPDs were used for all analyses, we later display normalized SPDs for each lamp, such that the peak of each SPD is 1 (See Section 3). This normalizing process enables visual comparison of lamps with varying electricity consumption rates and SPD profiles.

We selected one representative lamp in the range of 700-950 lm for each of four common lamp technologies (incandescent, INC; halogen, HAL; compact fluorescent, CFL; and light emitting diode, LED). See Table 3 for details about lamps discussed throughout this article.

Table 3. Metadata for example lamps, including year the SPD data were obtained, luminous efficacy, electricity consumption rate, lumen output, and luminous efficiency [54].

\begin{tabular}{ccccc}
\hline & INC & HAL & CFL & LED \\
\hline Description & Sylvania A19 & Sylvania PAR38 & EnergyStar Twister & EnergySmart BR30 \\
Year & 2013 & 2012 & 2014 & 2013 \\
Luminous efficacy [lm/W] & 14.1 & 11.0 & 63.3 & 70.0 \\
Electricity consumption [W] & 60 & 65 & 15 & 10 \\
Lumen output [lm] & 846.0 & 715.0 & 949.5 & 700.0 \\
Luminous efficiency [\%] & 2.06 & 1.61 & 9.27 & 10.25 \\
\hline
\end{tabular}

\section{Results}

Results are provided in Figure 5 for the spectral exergy-to-energy ratio for light $\left(\phi_{L, \lambda}\right)$, spectral luminous weighting functions $\left(f_{\lambda}\right)$, the normalized spectral emissive power of lamps $\left(\dot{E}_{E M, \lambda}\right.$ and $\left.\dot{X}_{E M, \lambda}\right)$, and spectral light emitted by lamps $\left(\dot{E}_{L, \lambda}\right.$ and $\left.\dot{X}_{L, \lambda}\right)$. Tables 4-6 give efficiencies $\left(\eta_{E, L, v}\right.$ and $\left.\eta_{X, L, v}\right)$ and exergy- to-energy 
ratios $\left(\phi_{L, \lambda}\right)$. All graphs were constructed and calculations were performed using $R$ [55]. See Supplementary information for data and $\mathrm{R}$ code [27].

\subsection{Spectral Exergy-To-Energy Ratio $\left(\phi_{L, \lambda}\right)$}

The upper-left graph in Figure 5 shows Equation (33). Note that exergy-to-energy ratio for light $\left(\phi_{L, \lambda}\right)$ is nearly 1 for all wavelengths of interest for illumination.
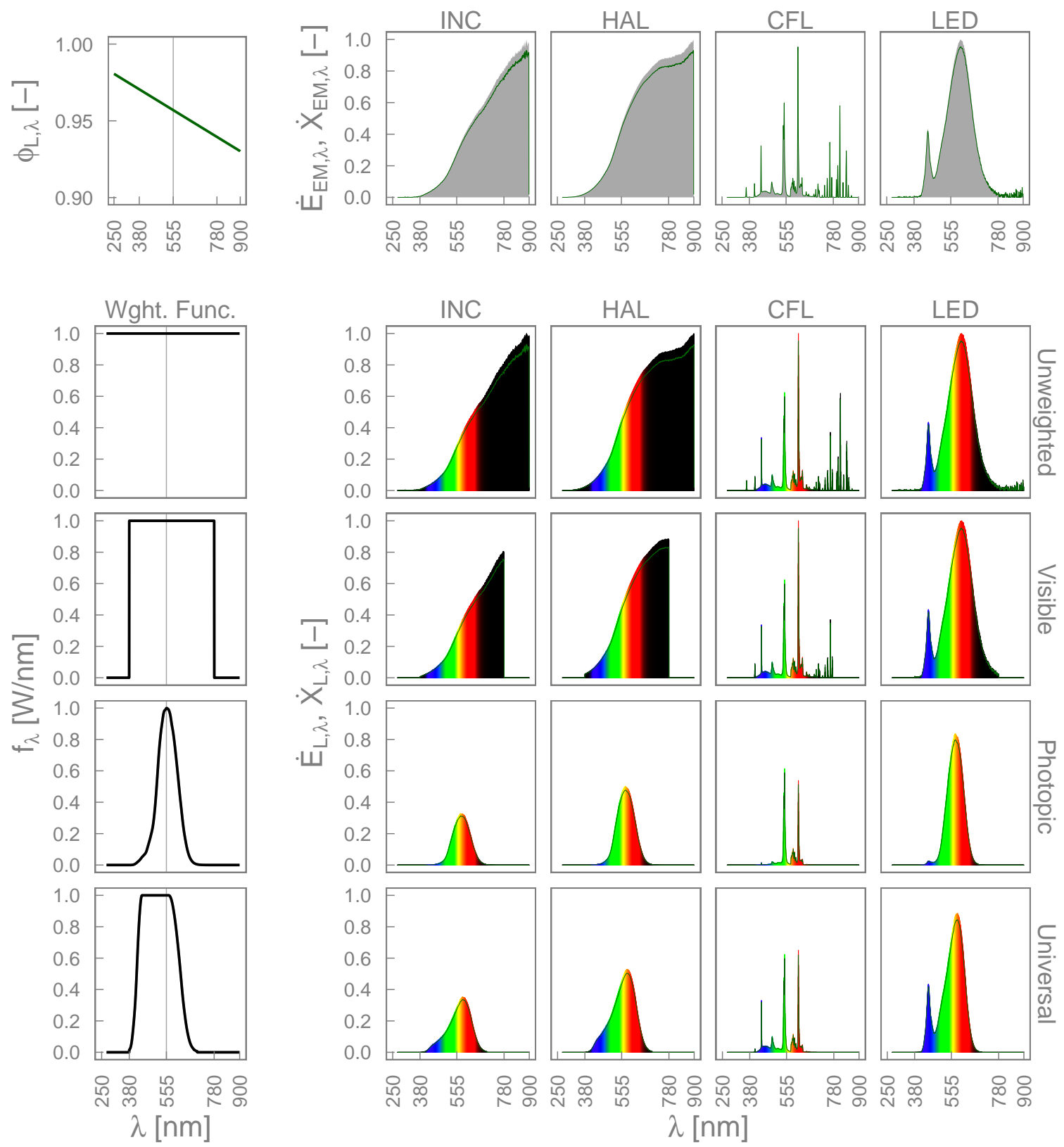

Figure 5. Upper left: The spectral exergy-to-energy ratio of light $\left(\phi_{L, \lambda}\right)$ from Equation (33). Top: Gray regions indicate spectral radiant power $\left(\dot{E}_{E M, \lambda}\right)$ for lamps in Table 3. Dark green lines show spectral exergy $\left(\dot{X}_{E M, \lambda}\right)$. Left: Spectral weighting functions $\left(f_{\lambda}\right)$, as shown in Table 2. Lower right: Rainbow-colored regions indicate the human perception of color and the portion of light deemed valuable for human perception. The tops of the rainbow regions give spectral light as energy $\left(\dot{E}_{L, \lambda}\right)$. The dark green lines show spectral light as exergy $\left(\dot{X}_{L, \lambda}\right)$. The spectral luminous power $\left(\Phi_{\lambda, p l}\right)$ is shown in the "Photopic" row. Peak spectral radiant power $\left(\dot{E}_{E M, \lambda}\right)$ values are normalized to 1 for each lamp. 
Table 4. Valuable energy efficiencies $\left(\eta_{E, L, v}\right.$, in \%) for each lamp and each weighting function $\left(f_{\lambda}\right)$, given by Equation (36). Note that for the incandescent (INC) and halogen (HAL) lamps, the unweighted energy efficiency $\left(\eta_{E, u w}\right)$ is underestimated, because the SPD data do not go beyond $899 \mathrm{~nm}$, despite INC and HAL emission beyond $900 \mathrm{~nm}$.

\begin{tabular}{ccccc}
\hline & INC & HAL & CFL & LED \\
\hline Unweighted $\left(\eta_{E, \text { uw }}\right)$ & 15.48 & 9.57 & 21.72 & 20.62 \\
Vis. spectrum $\left(\eta_{E, v i s}\right)$ & 8.84 & 6.13 & 18.27 & 20.40 \\
Photopic lum. $\left(\eta_{E, p l}\right)$ & 2.06 & 1.61 & 9.27 & 10.25 \\
Universal lum. $\left(\eta_{E, \text { univ }}\right)$ & 2.69 & 2.14 & 13.37 & 13.65 \\
\hline
\end{tabular}

Table 5. Exergy-to-energy ratios $\left(\phi_{L}\right)$ for each lamp and each weighting function $\left(f_{\lambda}\right)$, given by Equation (35).

\begin{tabular}{ccccc}
\hline & INC & HAL & CFL & LED \\
\hline Unweighted $\left(\phi_{L, u w}\right)$ & 0.943 & 0.944 & 0.953 & 0.954 \\
Vis. spectrum $\left(\phi_{L, v i s}\right)$ & 0.949 & 0.949 & 0.955 & 0.954 \\
Photopic lum. $\left(\phi_{L, p l}\right)$ & 0.955 & 0.955 & 0.956 & 0.956 \\
Universal lum. $\left(\phi_{L, \text { univ }}\right)$ & 0.956 & 0.957 & 0.958 & 0.957 \\
\hline
\end{tabular}

Table 6. Valuable exergetic efficiencies $\left(\eta_{X, L, v}\right.$, in \%) for each lamp and weighting function $\left(f_{\lambda}\right)$, given by Equation (37). Similar to Table 4 , the unweighted exergetic efficiency $\left(\eta_{X, u w}\right)$ is underestimated for the incandescent (INC) and halogen (HAL) lamps, because the SPD data do not go beyond $899 \mathrm{~nm}$, despite INC and HAL emission beyond $900 \mathrm{~nm}$.

\begin{tabular}{ccccc}
\hline & INC & HAL & CFL & LED \\
\hline Unweighted $\left(\eta_{X, \text { uw }}\right)$ & 14.59 & 9.04 & 20.69 & 19.67 \\
Vis. spectrum $\left(\eta_{X, v i s}\right)$ & 8.38 & 5.82 & 17.45 & 19.47 \\
Photopic lum. $\left(\eta_{X, p l}\right)$ & 1.97 & 1.54 & 8.86 & 9.79 \\
Universal lum. $\left(\eta_{X, \text { univ }}\right)$ & 2.58 & 2.05 & 12.81 & 13.06 \\
\hline
\end{tabular}

\subsection{Luminous Weighting Functions $\left(f_{\lambda}\right)$}

The four luminous weighting functions discussed in Section 2.2.1 and Table 2 are shown on the left side of Figure 5.

\subsection{Radiant Power $\left(\dot{E}_{E M, \lambda}\right.$ and $\left.\dot{X}_{E M, \lambda}\right)$}

The four graphs at the top of Figure 5 show normalized spectral radiant power $\left(\dot{E}_{E M, \lambda}\right)$ at the top of the gray region for each lamp. Applying Equation (33) to the four lamps identified in Section 2.2.2 gives spectral radiant power in exergy terms $\left(\dot{X}_{E M, \lambda}\right)$, shown by the dark green line. The areas of the gray regions $\left(\dot{E}_{E M}\right)$ are given by Equation (23). The areas beneath the dark green lines in all graphs are the exergy of light $\left(\dot{X}_{L}\right)$, given by Equation (34).

Note that exergy (dark green line) is very close to energy (top of the gray regions) for all lamps, because the exergy-to-energy ratio $\left(\phi_{L, \lambda}\right)$ is always close to 1 for EM wavelengths relevant to light. The difference between energy and exergy is greatest in the upper right of the graphs where both (a) emission is greater and (b) wavelength is longer.

\subsection{Luminous Power $\left(\dot{E}_{L, \lambda}\right.$ and $\left.\dot{X}_{L, \lambda}\right)$}

Figure 5 provides visual representation of the spectral energy and exergy of light for the four lamps and four weighting functions of Sections 2.2.1 and 2.2.2 and Tables 2 and 3, respectively. Each rainbow colored region shows the energy content of light (spectral luminous power) and is the spectral product of its row's weighting function and its column's lamp SPD. The areas of the rainbow colored regions $\left(\dot{E}_{L}\right)$ are given by Equation (27). The areas beneath the dark green lines $\left(\dot{X}_{L}\right)$ are given by Equation (34). 


\subsection{Energy Efficiencies $\left(\eta_{E, L, v}\right)$}

Valuable energy efficiencies $\left(\eta_{E, L, v}\right)$ of the various combinations of weighting functions and lamps are shown in Table 4. Note that when a luminous weighting function is specified, the lighting $(L)$ and valuable $(v)$ subscripts are implied and replaced by the weighting function specifier. (e.g., the valuable $(v)$ energy $(E)$ efficiency $(\eta)$ of light $(L)$ using the visible luminous weighting function (vis), $\eta_{E, L, v, v i s}$, is written unambiguously as $\eta_{E, v i s}$ for simplicity.)

\subsection{Exergy-To-Energy Ratio $\left(\phi_{L}\right)$}

Exergy-to-energy ratios $\left(\phi_{L}\right)$ of the various combinations of weighting functions and lamps are shown in Table 5.

\subsection{Exergetic Efficiencies $\left(\eta_{X, L, v}\right)$}

Valuable exergetic efficiencies $\left(\eta_{X, L, v}\right)$ of the various combinations of weighting functions and lamps are shown in Table 6.

\section{Discussion}

\subsection{Comparison between Conventional and Exact Methods to Calculating Exergetic Efficiency $\left(\eta_{X, L, v}\right)$}

The exact method for calculating the exergetic efficiency of lamps presented in Section 2.1.5 differs from the conventional method used in the societal exergy analysis community (Section 1.3). This section (a) adds detail to the conventional method and (b) evaluates the conventional method relative to the exact method, leading to three implications for societal exergy analysis (Section 4.1.2).

\subsubsection{Conventional and Exact Methods}

The conventional method (Section 1.3) estimates the valuable exergetic efficiency of lighting by the quotient of the theoretical minimum rate of energy required to emit one lumen and the actual rate of energy used to emit one lumen for a given lamp. The minimum and actual energy rates are obtained by inverting luminous efficacies. For a lamp, the quotient is between the lamp's luminous efficacy $(K)$ and the maximum luminous efficacy $\left(K_{\max }\right)$. Thus,

$$
\eta_{X, L, v} \approx \frac{\frac{1}{K_{\max }}}{\frac{1}{K}}=\frac{K}{K_{\max }},
$$

a restating of Equation (3).

Equation (43) shows that the luminous efficacy of a lamp $(K)$ is equal to the quotient of the luminous power $\left(\Phi_{p l}\right.$, Equation (42)), expressed in $1 \mathrm{~m}$, and the electricity consumption rate of the device $\left(\dot{W}_{\text {elect }, 1}\right.$ in Figure 4), expressed in W. Substituting Equation (43) into Equation (47) restates (with reference to Figure 4) valuable exergetic efficiency for the conventional method:

$$
\eta_{X, L, v} \approx \frac{\frac{(683 \mathrm{~lm} / \mathrm{W}) \int V_{\lambda} \dot{E}_{E M, \lambda, 3} \mathrm{~d} \lambda}{\dot{\mathrm{W}}_{\text {elect }, 1}}}{K_{\max }} .
$$

With recent advances in the fields of radiation thermodynamics and photometry (Section 2.1.4), it is now possible to determine the energy and exergy of light exactly, thereby relieving societal exergy practitioners of the need to estimate exergetic efficiency by the quotient of the minimum energy required to produce a lumen and the actual energy required to produce a lumen. Thus, we can evaluate the conventional method in light of recent advances, using exergetic efficiency $\left(\eta_{X, L, v}\right)$ as the point of comparison. 
Comparing Equation (48) (the conventional method) to Equation (37) (the exact method) reveals that the conventional method for calculating the exergetic efficiency of lighting is correct under the following conditions only:

(1) the maximum luminous efficacy $\left(K_{\max }\right)$ is taken to be $683 \mathrm{~lm} / \mathrm{W}$,

(2) $\phi_{L, \lambda}=1$ for all wavelengths, and

(3) the spectral luminous weighting function $\left(f_{\lambda}\right)$ is taken to be the photopic luminous weighting function $\left(V_{\lambda}\right)$.

Condition (a) shows that the correct assumption for maximum luminous efficacy in the conventional method is $K_{\max }=683 \mathrm{~lm} / \mathrm{W}$. Any other assumption is a mistake. The assumption in condition (b) is incorrect; the exergy-to-energy ratio for light $\left(\phi_{L, \lambda}\right)$ is not 1 (as shown in Equation (33)), but the conventional method assumes it is. Condition (c) highlights an unfortunate requirement of the conventional method, one that is lifted by the exact method.

When $K_{\max }$ is equal to $683 \mathrm{~lm} / \mathrm{W}$ and the weighting function is taken to be the photopic luminous weighting function $\left(V_{\lambda}\right)$, as they should for the conventional method, Equation (48) simplifies to

$$
\eta_{X, L, v} \approx \frac{\int V_{\lambda} \dot{E}_{E M, \lambda, 3} \mathrm{~d} \lambda}{\dot{W}_{\text {elect }, 1}}
$$

So the conventional method's estimate of a lamp's valuable exergetic efficiency (Equation (47)) reduces to Equation (49), which is the same as Equation (36), the valuable energy efficiency of a lamp, if $f_{\lambda}=V_{\lambda}$. That is to say, one interpretation of the conventional method is that it incorrectly assumes the exergetic efficiency of a lamp to be its energy efficiency.

\subsubsection{Implications for Societal Exergy Analysis}

The above comparison between the conventional method (Section 4.1.1) and the exact method (Section 2.1) raises three implications for societal exergy analysis. First, with the conventional method, the practitioner is required to select a value for maximum luminous efficacy $\left(K_{\max }\right)$, the denominator of Equation (47). The choice of $K_{\max }$ can make a significant difference to the results. The correct value for $K_{\max }$ is $683 \mathrm{~lm} / \mathrm{W}$, as discussed in Section 4.1.1. We showed in Section 1.3 that some practitioners have mistakenly, we now know, taken $K_{\max }$ to be $220 \mathrm{~lm} / \mathrm{W}$ or $400 \mathrm{~lm} / \mathrm{W}$, thereby overestimating exergetic efficiency of lighting $\left(\eta_{X, L, v}\right)$ with the conventional method by a factor of $\frac{683 \mathrm{~lm} / \mathrm{W}}{220 \mathrm{~lm} / \mathrm{W}}=3.1$ or $\frac{683 \mathrm{~lm} / \mathrm{W}}{400 \mathrm{~lm} / \mathrm{W}}=1.7$, respectively.

Second, to obtain the correct exergetic efficiency of lighting, practitioners must reject the conventional method assumption that $\phi_{L, \lambda}=1$. Recent progress in the exergy of radiation enables this rejection, following the methods of Section 2.1.4. Specifically, the spectral exergy-to-energy ratio of light $\left(\phi_{L, \lambda}\right)$ of Equation (33) and Figure 5 should be used. We note, however, that $\phi_{L, \lambda}$ is close to 1 for all wavelengths of interest to illumination. Happily, the conventional method was not far wrong.

Third, in the conventional method, the practitioner is required to use the photopic luminous weighting function $\left(V_{\lambda}\right)$ for the spectral luminous weighting function $\left(f_{\lambda}\right)$. However, it is not certain that the photopic luminous weighting function is the best choice. In fact, we later recommend replacing the photopic luminous weighting function $\left(V_{\lambda}\right)$ by the universal luminous weighting function $\left(U_{\lambda}\right)$. (See Section 4.2.2).

\subsection{Recommendations}

We provide three recommendations for societal exergy practitioners: (a) use the exact method of Section 2 when possible, i.e., when SPD data are available for a lamp or lamp technology (Section 4.2.1), (b) use the universal luminous weighting function $\left(U_{\lambda}\right)$ always (Section 4.2.2), and (c) use an approximate method when luminous efficacy $(K)$ data are available, but SPD data are not (Section 4.2.3). 


\subsubsection{Recommendation for the Exact Method}

Our first recommendation is for use of the exact method (Section 2.1.5) for determining the valuable exergetic efficiency of lamps $\left(\eta_{X, L, v}\right)$ when SPD data are available. The exact method provides the following benefits over the conventional method:

(a) it is free of any assumptions for the maximum luminous efficacy $\left(K_{\max }\right)$,

(b) it uses a non-unity spectral exergy-to-energy ratio, no longer assuming $\phi_{L, \lambda}=1$, and

(c) it allows choices for the spectral luminous weighting function $\left(f_{\lambda}\right)$, no longer requiring $f_{\lambda}=V_{\lambda}$, thereby enabling our second recommendation, namely use of the universal luminous weighting function $\left(U_{\lambda}\right)$.

\subsubsection{Recommendation for the Universal Luminous Weighting Function $\left(U_{\lambda}\right)$}

We recognize that the choice of spectral weighting function $\left(f_{\lambda}\right)$ remains contentious $[45,51,56,57]$. That said, we suggest that the choice of weighting function in societal exergy analysis should be appropriate for each lamp's application. Our second recommendation is for use of the universal luminous weighting function $\left(U_{\lambda}\right)$ in societal exergy analysis when the purpose of lamps is illumination.

For the application of illumination, we note that human perception of light and color diminishes rapidly above $700 \mathrm{~nm}$, as shown by Figure 5 . This decline in human eye sensitivity toward the infra-red region is captured well by the photopic luminous weighting function $\left(V_{\lambda}\right)$.

However, it is also known that short wavelength EM radiation (bluer light) provides physiological benefits, such as the suppression of melanopsin and the regulation of circadian rhythms [56]. The photopic luminous weighting function $\left(V_{\lambda}\right)$ does not capture the importance of short wavelength EM radiation, attenuating human perception nearly equally in the blue and red regions of the visible spectrum.

Societal exergy analysis implicitly adopts the photopic luminous weighting function $\left(V_{\lambda}\right)$ when it applies the conventional method for calculating the exergetic efficiency of lighting (See Section 4.1.1). For lamps whose purpose is illumination, we believe that, instead, the universal luminous weighting function $\left(U_{\lambda}\right)$ is most appropriate. (See also Rea and Bierman [51]). We provide three arguments in support of this recommendation.

First, the universal luminous weighting function $\left(U_{\lambda}\right)$ accounts for the sensitivity of all five types of light receptors in the human eye, whereas the photopic luminous weighting function $\left(V_{\lambda}\right)$ does not.

Second, to obtain the benefits of blue light, many lamps are designed with a blue spike in the region of $480 \mathrm{~nm}$, the peak of the melanopsin suppression action spectrum [58]. (For example, see the blue spike in the SPD $\left(\dot{E}_{E M, \lambda}\right)$ for the LED lamp in Figure 5). The universal luminous weighting function $\left(U_{\lambda}\right)$ correctly includes the energy or exergy of blue spikes in the numerator of efficiency calculations, thereby correctly elevating the efficiency of lamps that contain a blue spike compared to the photopic luminous weighting function.

Third, manufacturers who design lamps with blue spikes do not get credit for their efforts, because the industry-standard measure of lighting efficiency, luminous efficacy $(K)$, uses the photopic luminous weighting function $\left(V_{\lambda}\right)$. This state of affairs could encourage lamp manufacturers to reduce short wavelength output of lamps, even when short wavelength EM radiation would provide physiological benefits. Adopting the universal luminous weighting function will alleviate the incentive for manufacturers to minimize the size of blue spikes, providing a greater range of options for the design of SPDs for lamps that produce white light.

The conventional method for estimating lamp efficiency is bound by the use of the photopic luminous weighting function. However, a switch away from the photopic luminous weighting function $\left(V_{\lambda}\right)$ toward the universal luminous weighting function $\left(U_{\lambda}\right)$ is made possible by the exact method described in Section 2.1, so long as SPD data are available. In the absence of SPD data, we recommend an approximate method, as set out in the next section. 


\subsubsection{Recommendation for an Approximate Method}

Section 4.1.1 shows that the conventional method does not require SPD information, but it produces energy efficiency (instead of exergetic efficiency) while requiring the use of photopic luminous weighting function $\left(\eta_{E, p l}\right)$. In contrast, we recommend that, in the absence of SPD data, societal exergy practitioners calculate exergetic efficiency with the universal luminous weighting function $\left(\eta_{X, \text { univ }}\right)$. Thus, our third recommendation is for an approximate method to determine the valuable exergetic efficiency of lamps $\left(\eta_{X, L, v}\right)$ when SPD data are not available but luminous efficacy data $(K)$ are. Results from the exact method provide guidance for development of an approximate method.

We suggest the following two-step process: using the conventional method as a starting point,

1. move from valuable energy efficiency $\left(\eta_{E, p l}\right)$ to valuable exergetic efficiency $\left(\eta_{X, p l}\right)$ using an average exergy-to-energy ratio $\left(\bar{\phi}_{L, p l}\right)$ and

2. move from valuable exergetic efficiency determined with the photopic luminous weighting function $\left(\eta_{X, p l}\right)$ to valuable exergetic efficiency determined with the universal luminous weighting function $\left(\eta_{X, \text { univ }}\right)$ using an average ratio between those efficiencies, the average photopic-touniversal conversion factor $\left(\bar{\gamma}_{p l \rightarrow u n i v}\right)$.

Estimating the average exergy-to-energy ratio $\left(\bar{\phi}_{L, p l}\right)$

We calculated the exergy-to-energy ratio for a sample of lamps from the LSPDD [54] using Equation (35) with $f_{\lambda}=V_{\lambda}$. (The sample consists of 45 lamp SPDs representing six technologies: INC, HAL, CFL, LED, MH (metal halide), and HPS (high pressure sodium). The average value for the exergy-to-energy ratio is $\bar{\phi}_{L, p l}=0.956$ with a remarkably small standard deviation of $\sigma_{\phi_{L, p l}}=0.00037$. Table 7 shows statistics for the exergy-to-energy ratio $\left(\bar{\phi}_{L, p l}\right)$ by lighting technology.

Table 7. The mean $\left(\bar{\phi}_{L, p l}\right)$, standard deviation $\left(\sigma_{\phi_{L, p l}}\right)$, and sample size $(n)$ of the exergy-to-energy ratio when using the photopic luminous weighting function, by lighting technology.

\begin{tabular}{ccccccc}
\hline & INC & HAL & CFL & LED & MH & HPS \\
\hline $\bar{\phi}_{L, p l}$ & 0.955 & 0.956 & 0.956 & 0.956 & 0.956 & 0.955 \\
$\sigma_{\phi_{L, p l}}$ & 0.000148 & 0.000097 & 0.000419 & 0.000361 & 0.000196 & \\
$n$ & 11 & 10 & 10 & 10 & 3 & 1 \\
\hline
\end{tabular}

Estimating the average photopic-to-universal conversion factor $\left(\bar{\gamma}_{p l \rightarrow \text { univ }}\right)$

Similarly, we obtained $\gamma_{p l \rightarrow \text { univ }}$ for each lamp (i) by taking the quotient of efficiencies:

$$
\gamma_{p l \rightarrow \text { univ }, i}=\frac{\eta_{X, u n i v, i}}{\eta_{X, p l, i}}
$$

Because a greater proportion of each SPD is considered to be light by the universal luminous weighting function $\left(U_{\lambda}\right)$ compared to the photopic luminous weighting function $\left(V_{\lambda}\right), \gamma_{p l \rightarrow \text { univ }}$ is expected to be greater than 1 . The average value of the photopic-to-universal factor across our population of lamps was $\bar{\gamma}_{p l \rightarrow \text { univ }}=1.36$, with a small standard deviation of $\sigma_{\gamma_{p l \rightarrow u n i v}}=0.095$. Table 8 shows statistics for the photopic-to-universal factor $\left(\bar{\gamma}_{p l \rightarrow \text { univ }}\right)$ by lighting technology.

Table 8. The mean $\left(\bar{\gamma}_{p l \rightarrow \text { univ }}\right)$, standard deviation $\left(\sigma_{\gamma_{p l \rightarrow u n i v}}\right)$, and sample size $(n)$ of the photopic-touniversal factor, by lighting technology.

\begin{tabular}{ccccccc}
\hline & INC & HAL & CFL & LED & MH & HPS \\
\hline $\bar{\gamma}_{p l \rightarrow \text { univ }}$ & 1.32 & 1.36 & 1.38 & 1.34 & 1.51 & 1.19 \\
$\sigma_{\gamma_{p l \rightarrow \text { univ }}}$ & 0.029 & 0.031 & 0.138 & 0.097 & 0.048 & \\
$n$ & 11 & 10 & 10 & 10 & 3 & 1 \\
\hline
\end{tabular}




\section{Implementing the approximate method}

The approximate method for determining the valuable exergetic efficiency of a lamp is implemented by the following equation

$$
\eta_{X, \text { univ }} \approx \bar{\phi}_{L, p l} \bar{\gamma}_{p l \rightarrow \text { univ }} \frac{K}{683 \mathrm{~lm} / \mathrm{W}},
$$

which is a modification of Equation (47) that approximates the move from energy to exergy assuming the photopic luminous weighting function (via $\bar{\phi}_{L, p l}$ ) and the move from the photopic luminous weighting function to the universal luminous weighting function in the exergy space (via $\bar{\gamma}_{p l \rightarrow \text { univ }}$ ).

When the lamp technology is unknown, overall average values can be used for $\bar{\phi}_{L, p l}$ and $\bar{\gamma}_{p l \rightarrow \text { univ }}$ :

$$
\eta_{X, \text { univ }} \approx(0.956)(1.36) \frac{K}{683 \mathrm{~lm} / \mathrm{W}}=1.30 \frac{K}{683 \mathrm{~lm} / \mathrm{W}} .
$$

If the lamp technology is known, $\bar{\phi}_{L, p l}$ and $\bar{\gamma}_{p l \rightarrow \text { univ }}$ values from Tables 7 and 8 could be used instead of the averages across all technologies shown in Equation (52).

Table 9 summarizes the valuable exergetic efficiency for the four representative lamps (INC, HAL, CFL, LED) and the three methods (conventional, exact, and approximate).

Table 9. Valuable exergetic efficiencies (in \%) for each of the three methods (conventional, exact, and approximate) and each of the four example lamps (INC, HAL, CFL, LED). Note that the conventional method row is the same as row 3 of Table 4 . The exact method row is the same as row 4 of Table 6 . The approximate method row uses the values for $\bar{\phi}_{L, p l}$ and $\bar{\gamma}_{p l \rightarrow \text { univ }}$ shown in Equation (52).

\begin{tabular}{ccccc}
\hline & INC & HAL & CFL & LED \\
\hline Conventional method $\left(\eta_{E, p l}\right)$ & 2.06 & 1.61 & 9.27 & 10.25 \\
Exact method $\left(\eta_{X, \text { univ }}\right)$ & 2.58 & 2.05 & 12.81 & 13.06 \\
Approximate method (Equation $(52))$ & 2.68 & 2.09 & 12.03 & 13.30 \\
\hline
\end{tabular}

\subsection{Aggregate Lighting Efficiencies}

Societal exergy analyses are normally conducted at the sectoral or economy-wide scale, so practitioners must weight per-lamp-technology efficiencies by each technology's usage fraction. Two types of data are needed for a given period of interest, typically a year: (a) valuable exergetic efficiency data for each lamp technology $\left(\eta_{X, u n i v, i}\right)$ and (b) proportion of lighting electricity consumption by lamp technology $\left(\theta_{i}\right)$, where $i$ denotes individual lighting technologies.

Item (a) is the result of applying the exact method to each lamp technology but depends on the availability of representative SPDs for each technology, which are not often known. Instead, the most common measure of lighting efficiency reported for a lamp technology is the luminous efficacy $(K)$. Therefore, to develop an aggregate measure of lighting efficiency, luminous efficacies must be converted into valuable exergetic efficiencies by the approximate method. (See Section 4.2.3).

Data for item (b) are in the form of the fraction of lighting electricity consumed by each lamp technology. Such data (and luminous efficacy values, $K_{i}$ ) can be obtained from the US DOE's Lighting Market Characterization reports [24-26] for the USA for the following lamp technologies: incandescent, halogen, compact fluorescent, linear fluorescent, high intensity discharge, LED, and other.

When SPDs are available, the exact method can be used to determine the valuable exergetic efficiency of each lighting technology $(i)$, and the aggregate valuable exergetic lighting efficiency for a particular year can be found by

$$
\eta_{X, \text { univ, agg }}=\sum_{i} \theta_{i} \eta_{X, \text { univ }, i}
$$


When SPDs are not available, the approximate method can be used as follows:

$$
\eta_{X, \text { univ,agg }} \approx \sum_{i} \theta_{i} \bar{\phi}_{L, p l} \bar{\gamma}_{p l \rightarrow \text { univ }} \frac{K_{i}}{683 \mathrm{~lm} / \mathrm{W}} .
$$

\section{Summary and Future Work}

Several recent developments in the fields of radiation thermodynamics and photometry (the spectral exergy-to-energy ratio, $\phi_{L, \lambda}$, and the photon effective temperature, $T_{\lambda}$ ) have enabled a re-evaluation of the exergy of light and the exergetic efficiency of electric lamps applicable to societal exergy analysis. We built upon those advances to provide clear and rigorous definitions of the energy and exergy of light. We developed a novel exact method for determining the exergetic efficiency of lamps involving the spectral exergy-to-energy ratio $\left(\phi_{L, \lambda}\right)$, a luminous weighting function $\left(f_{\lambda}\right)$, and broad-spectrum lamp luminous power $\left(\dot{E}_{E M}\right)$. We showed that the exact method (a) is free of any assumptions for the maximum luminous efficacy $\left(K_{\max }\right),(\mathrm{b})$ uses a non-unity spectral exergy-to-energy ratio $\left(\phi_{L, \lambda}\right)$, and (c) allows choices for the spectral luminous weighting function $\left(f_{\lambda}\right)$. Items (a)-(c) are improvements over the conventional method. The exact method requires the availability of a lamp's spectral power distribution. For cases when a spectral power distribution is not available, we developed a novel approximate method, involving surprisingly stable values of the exergy-to-energy ratio $\left(\phi_{L}\right)$ and the photopic-to-universal conversion factor $\left(\gamma_{p l \rightarrow \text { univ }}\right)$ across lighting technologies. Finally, we provided recommendations for societal exergy practitioners, namely to use (a) the exact method when a lamp's spectral power distribution is available, (b) the universal luminous weighting weighting function $\left(U_{\lambda}\right)$, and $(c)$ the approximate method when luminous efficacy is known but spectral power distribution is not.

Future work could include (a) investigating additional lighting technologies to assess the stability of the average exergy-to-energy ratio $\left(\bar{\phi}_{L, p l}\right)$ and the average photopic-to-universal conversion factor $\left(\bar{\gamma}_{p l \rightarrow \text { univ }}\right)$ across lighting technologies, (b) applying the exact method to understand the evolution of lighting technology relative to the maximum possible reductions in lighting energy consumption [59] (via gains in lamp luminous efficacy $(K)$ and valuable exergetic efficiency, $\eta_{X, L, v}$ ), (c) understanding the effect of lamp "waste" heat on lamp efficiency (lamp heat is beneficial when it displaces energy for winter space heating but detrimental when it adds to summer cooling loads), and (d) pushing toward the services stage of the energy conversion chain to assess the effects of waste light (caused by excessive intensity, lighting that falls on surfaces that do not require illumination, or under-utilization of light due to under-occupancy of spaces).

Supplementary Materials: The following are available online at https:/ / doi.org/10.5518/865 [27]: sources for the luminous efficacy values in Figure 2, sources for the weighting functions and SPDs displayed in Figure 5, instructions and $\mathrm{R}$ code for reproducing the metrics and figures in this paper, and a blank excel workbook template in the required format for the insertion of spectral power distribution data by the user.

Author Contributions: Conceptualization: M.K.H., Z.M., E.A., and P.E.B.; methodology: M.K.H., Z.M., and E.A.; software: M.K.H., Z.M., and E.A.; validation: M.K.H. and Z.M.; formal analysis: M.K.H., Z.M., and E.A.; investigation: M.K.H. and Z.M.; resources: M.K.H.; data curation: M.K.H. and Z.M.; writing-original draft preparation: M.K.H., Z.M., E.A., and P.E.B.; writing-review and editing: M.K.H., Z.M., E.A., and P.E.B.; visualization: M.K.H., Z.M., and E.A.; supervision: M.K.H. and P.E.B.; project administration: M.K.H. and P.E.B.; funding acquisition: P.E.B. All authors have read and agreed to the published version of the manuscript.

Funding: Zeke Marshall's and Paul E. Brockway time was funded by the UK Research Council under EPSRC Fellowship award EP/R024254/1. Emmanuel Aramendia's time was funded by the University of Leeds (School of Earth and Environment). Matthew Kuperus Heun has no funding to declare.

Acknowledgments: The authors thank James D. Hooker for the use of data from the Museum of Electric Lamp Technology [22], Alfonso Delgado-Bonal for his advice on the state of the discourse regarding the exergy-to-energy ratio of light, Pedro J. Aphalo for his open-source software suite r4phototbiology [10], Martin Aubè and Johanne Roby for the use of their Light Spectral Power Distribution Database (LSPDD) [54], Andrew Stockman and other members of the Colour and Vision Research Laboratory for their open-source database from which we obtained data for the photopic luminous weighting function [50], Mark S. Rea and Andrew Bierman for the use of the universal luminous weighting function [51], and Micheal Royer for his advice regarding photometric data. 
Conflicts of Interest: The authors declare no conflict of interest. The funders had no role in the design of the study; in the collection, analyses, or interpretation of data; in the writing of the manuscript; or in the decision to publish the results.

\section{Nomenclature}

The following symbols, greek letters, subscripts, and abbreviations are used in this manuscript:

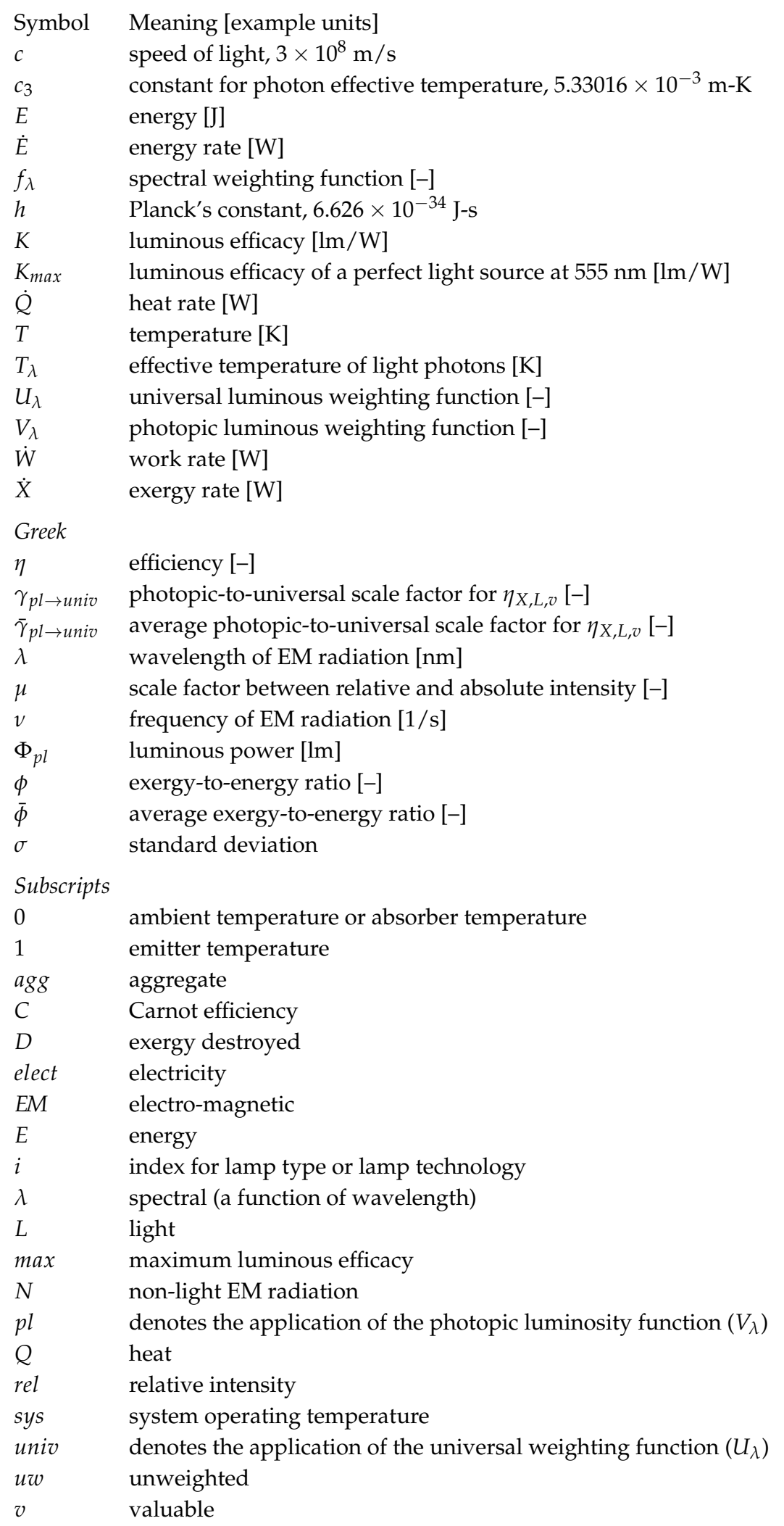




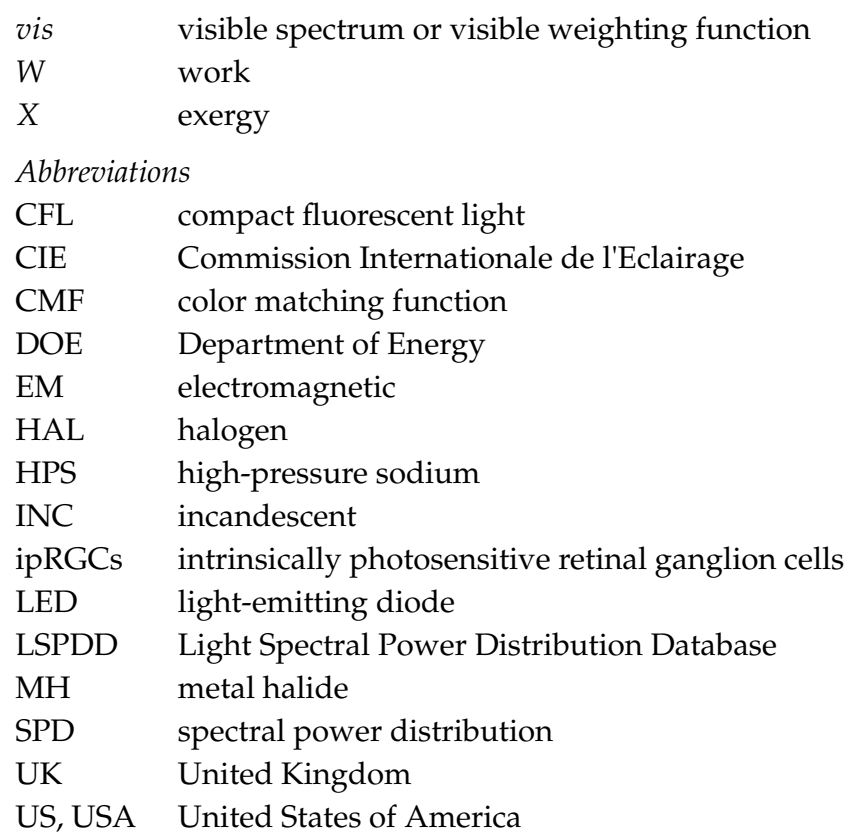

\section{References}

1. Waide, P.; Tanishima, S. Light's Labour's Lost: Policies for Energy-Efficient Lighting; OECD Publishing: Paris, France, 2006.

2. Abergel, T. "Lighting" in Tracking Buildings 2020, International Energy Agency. 2020. Available online: https:/ / www.iea.org/reports/lighting (accessed on 17 August 2020).

3. Pattison, P.M.; Hansen, M.; Tsao, J.Y. LED lighting efficacy: Status and directions. C. R. Phys. 2018, 19, $134-145$. [CrossRef]

4. Fouquet, R.; Pearson, P.J. Seven Centuries of Energy Services: The Price and Use of Light in the United Kingdom (1300-2000). Energy J. 2006, 27, 139-177. [CrossRef]

5. Nordhaus, W.D. Historical Reassessments of Economic Progress: Do Real-Output and Real-Wage Measures Capture Reality? The History of Lighting Suggests Not; University of Chicago Press: Chicago, IL, USA, 1996; pp. 27-70.

6. Whiting, K.; Carmona, L.G.; Brand-Correa, L.; Simpson, E. Illumination as a material service: A comparison between Ancient Rome and early 19th century London. Ecol. Econ. 2020, 169, 106502. [CrossRef]

7. Ayres, R.U.; Ayres, L.W.; Pokrovsky, V. On the efficiency of US electricity usage since 1900. Energy 2005, 30, 1092-1145. [CrossRef]

8. Urry, L.A.; Cain, M.L.; Wasserman, S.A.; Minorsky, P.V.; Reece, J.B. Campbell Biology: A Global Approach; Pearson: New York, NY, USA, 2017.

9. Commission Internationale de l'Eclairage. Fundamental Chromaticity Diagram with Physiological Axes. Parts 1 and 2. Technical Report 170-1; Technical Report; Commission Internationale de l'Eclairage: Paris, France, 2005.

10. Aphalo, P.J. r4photobiology suite: Spectral irradiance. UV4Plants Bull. 2015, 2015, 21-29. [CrossRef]

11. Schubert, E.F. Light-Emitting Diodes; Cambridge University Press: Cambridge, UK, 2006; [CrossRef]

12. Bejan, A.; Tsatsaronis, G. Thermal Design and Optimization; John Wiley \& Sons: New York, NY, USA, 1996.

13. Durmayaz, A.; Yavuz, H. Exergy analysis of a pressurized-water reactor nuclear-power plant. Appl. Energy 2001, 69, 39-57. [CrossRef]

14. Joybari, M.M.; Hatamipour, M.S.; Rahimi, A.; Modarres, F.G. Exergy analysis and optimization of R600a as a replacement of R134a in a domestic refrigerator system. Int. J. Refrig. 2013, 36, 1233-1242. [CrossRef]

15. Bobbo, S.; Fedele, L.; Curcio, M.; Bet, A.; De Carli, M.; Emmi, G.; Poletto, F.; Tarabotti, A.; Mendrinos, D.; Mezzasalma, G.; et al. Energetic and exergetic analysis of low global warming potential refrigerants as substitutes for R410A in ground source heat pumps. Energies 2019, 12, 3538. [CrossRef]

16. Zwierzchowski, R.; Wołowicz, M. Energy and Exergy Analysis of Sensible Thermal Energy Storage-Hot Water Tank for a Large CHP Plant in Poland. Energies 2020, 13, 4842. [CrossRef]

17. Nakićenović, N.; Gilli, P.V.; Kurz, R. Regional and global exergy and energy efficiencies. Energy 1996, 21, 223-237. [CrossRef] 
18. Guevara, Z.; Sousa, T.; Domingos, T. Insights on Energy Transitions in Mexico from the Analysis of Useful Exergy 1971-2009. Energies 2016, 9, 488. [CrossRef]

19. Heun, M.K.; Brockway, P.E. Meeting 2030 primary energy and economic growth goals: Mission impossible? Appl. Energy 2019, 251, 1-24. [CrossRef]

20. Ver Beek, N.; Vindel, E.; Heun, M.K.; Brockway, P.E. Quantifying the Environmental Impacts of Cookstove Transitions: A Societal Exergy Analysis Based Model of Energy Consumption and Forest Stocks in Honduras. Energies 2020, 13, 3206. [CrossRef]

21. Rea, M.S.; Bullough, J.D. Application efficacy. J. Illum. Eng. Soc. 2001, 30, 73-96. [CrossRef]

22. Hooker, J.D. LampTech: The Museum of Electric Lamp Technology. Available online: http://www.lamptech. co.uk/ (accessed on 17 August 2020).

23. U.S. Department of Energy. ENERGY STAR Certified Light Bulbs Version 2.0. Available online: https:// data.energystar.gov / Active-Specifications /ENERGY-STAR-Certified-Light-Bulbs-Version-2-0/ebgj-qsf7 (accessed on 17 August 2020).

24. Brodrick, J. 2001 US Lighting Market Characterization, Volume I: National Lighting Inventory and Energy Consumption Estimate; Technical Report; Navigant Consulting, Inc., US Department of Energy: Washington, DC, USA, 2002. Available online: https://www1.eere.energy.gov/buildings/publications/pdfs/ssl/lmc_ vol1_final.pdf (accessed on 17 August 2020).

25. Ashe, M.; Chwastyk, D.; de Monasterio, C.; Gupta, M.; Pegors, M. 2010 US Lighting Market Characterization; Technical Report; Navigant Consulting, Inc., US Department of Energy: Washington, DC, USA, 2012. Available online: https:/ / www1.eere.energy.gov/buildings/publications/pdfs/ssl/2010-lmc-final-jan-2012. pdf (accessed on 17 August 2020).

26. Buccitelli, N.; Elliott, C.; Schober, S.; Yamada, M. 2015 US Lighting Market Characterization; Technical Report; Navigant Consulting, Inc., US Department of Energy: Washington, DC, USA, 2017. Available online: https:/ / www.energy.gov/sites/prod/files/2017/12/f46/lmc2015_nov17.pdf (accessed on 17 August 2020).

27. Heun, M.K.; Marshall, Z.; Aramendia, E.; Brockway, P.E. Data Associated with "The Energy and Exergy of Light with Application to Societal Exergy Analysis"; Leeds University: Leeds, UK, 2020. [CrossRef]

28. Tsao, J.Y.; Waide, P. The world's appetite for light: Empirical data and trends spanning three centuries and six continents. LEUKOS J. Illum. Eng. Soc. N. Am. 2010, 6, 259-281. [CrossRef]

29. Sousa, T.; Brockway, P.E.; Cullen, J.M.; Henriques, S.T.; Miller, J.; Serrenho, A.C.; Domingos, T. The Need for Robust, Consistent Methods in Societal Exergy Accounting. Ecol. Econ. 2017, 141, 11-21. [CrossRef]

30. Summers, C. The Conversion of Energy. Sci. Am. 1971, 225, 149-160. [CrossRef]

31. Ayres, R.U.; Ayres, L.W.; Warr, B. Exergy, power and work in the US economy, 1900-1998. Energy 2003, 28, 219-273. [CrossRef]

32. US Department of Energy (DoE). 2010 Buildings Energy Data Book; Technical Report; US Department of Energy: Washington, DC, USA, 2011.

33. Tsao, J.Y.; Saunders, H.D.; Creighton, J.R.; Coltrin, M.E.; Simmons, J.A. Solid-state lighting: An energyeconomics perspective. J. Phys. D Appl. Phys. 2010, 43, 354001. [CrossRef]

34. Kondo, K. Energy and exergy utilization efficiencies in the Japanese residential/commercial sectors. Energy Policy 2009, 37, 3475-3483. [CrossRef]

35. Serrenho, A.G.C.H. Useful Work as an Energy End-Use Accounting Method: Historical and Economic Transitions and European Patterns. Ph.D. Thesis, Instituto Superior Técnico, University of Lisbon, Lisbon, Portugal, 2014.

36. Paoli, L.; Cullen, J. Technical limits for energy conversion efficiency. Energy 2020, 192, 1-12. [CrossRef]

37. Haitz, R.; Kish, F.; Tsao, J.; Nelson, J. The Case for a National Research Program on Semiconductor Lighting; Sandia Report SAND2000-1612; Sandia National Laboratory: Albuquerque, New Mexico, Mexico, 2000. Available online: https://prod-ng.sandia.gov/techlib-noauth/access-control.cgi/2000/001612.pdf (accessed on 17 August 2020).

38. Graydon, O.; Jenkins, A.; Pei Chin Won, R.; Gevaux, D. Haitz's law. Nat. Photonics 2007, 1. [CrossRef]

39. Thompson, B. An Experimental Enquiry Concerning the Source of the Heat which is Excited by Friction. Philos. Trans. R. Soc. Lond. 1798, 88, 80-102. [CrossRef]

40. Benenson, W.; Harris, J.W.; Stöcker, H.; Lutz, H. Handbook of Physics; Springer Science \& Business Media: New York, NY, USA, 2006. 
41. Anderson, R.R.; Parrish, J.A. The Optics of Human Skin. J. Investig. Dermatol. 1981, 77, 13-19. [CrossRef] [PubMed]

42. Jones, L. Thermal Touch. In Scholarpedia of Touch; Prescott, T.J., Ahissar, E., Izhikevich, E., Eds.; Scholarpedia, Atlantis Press: Paris, France, 2016; pp. 257-262. [CrossRef]

43. Shan, S.; Zhou, Z. Second law analysis of spectral radiative transfer and calculation in one-dimensional furnace cases. Entropy 2019, 21, 461. [CrossRef]

44. Petela, R. Exergy of heat radiation. J. Heat Transf. 1964. [CrossRef]

45. Delgado-Bonal, A. Entropy of radiation: The unseen side of light. Sci. Rep. 2017, 7, 1-11. [CrossRef]

46. Zhou, Z.; Shan, S.; Chen, L.; Zhang, Y. Exergy of blackbody radiation and monochromatic photon. Int. J. Thermophys. 2017, 38, 57. [CrossRef]

47. Chen, Z.; Mo, S.; Hu, P. Recent progress in thermodynamics of radiation-Exergy of radiation, effective temperature of photon and entropy constant of photon. Sci. China Ser. Technol. Sci. 2008, 51, 1096. [CrossRef]

48. Liu, L. Comment on "Recent progress in thermodynamics of radiation-Exergy of radiation, effective temperature of photon and entropy constant of photon". Sci. China Ser. Technol. Sci. 2009, 52, 1809-1810. [CrossRef]

49. Rossing, T.D.; Chiaverina, C.J. Light Science: Physics and the Visual Arts, 2nd ed.; Springer Nature: Cham, Switzerland, 2019. [CrossRef]

50. Colour \& Vision Research Laboratory, Institution of Opthalmology, University College London. CIE (2008) Physiologically-Relevant 2-Degree V( $\lambda$ ) Luminous Efficiency Functions. 2008. Available online: http:/ / www. cvrl.org/ (accessed on 17 August 2020).

51. Rea, M.S.; Bierman, A. A new rationale for setting light source luminous efficacy requirements. Light. Res. Technol. 2018, 50, 340-359. [CrossRef]

52. Roby, J.; Aubé, M.; Morin-Paulhus, A.; Beauchesne, W.; Cyr, L.O. LSPDD: Lamp Spectral Power Distribution Database. Available online: http://galileo.graphycs.cegepsherbrooke.qc.ca/app/en/home (accessed on 17 August 2020).

53. Miguel, A.S.D.; Aubé, M.; Zamorano, J.; Kocifaj, M.; Roby, J.; Tapia, C. Sky Quality Meter measurements in a colour-changing world. Mon. Not. R. Astron. Soc. 2017, 467, 2966-2979. [CrossRef]

54. Aubé, M.; Roby, J.; Kocifaj, M. Evaluating Potential Spectral Impacts of Various Artificial Lights on Melatonin Suppression, Photosynthesis, and Star Visibility. PLoS ONE 2013, 8, e67798. [CrossRef]

55. R Core Team. R: A Language and Environment for Statistical Computing; R Foundation for Statistical Computing: Vienna, Austria. Available online: https:/ /www.r-project.org (accessed on 17 August 2020).

56. Pattison, P.M.; Tsao, J.Y.; Brainard, G.C.; Bugbee, B. LEDs for photons, physiology and food. Nature 2018, 563, 493-500. [CrossRef] [PubMed]

57. Royer, M. Spectral Power Distribution: The Building Block of Applied Lighting. Presentation at 2016 Solid State Lighting Technology Development Workshop, Denver, CO, USA, 16-17 November 2016. Available online: https:/ / www.energy.gov/sites/prod/files/2016/11/f34/royer_spectral-power-dist_denver2016. pdf (accessed on 17 August 2020).

58. Lucas, R.J.; Peirson, S.N.; Berson, D.M.; Brown, T.M.; Cooper, H.M.; Czeisler, C.A.; Figueiro, M.G.; Gamlin, P.D.; Lockley, S.W.; O'Hagan, J.B.; et al. Measuring and using light in the melanopsin age. Trends Neurosci. 2014, 37, 1-9. [CrossRef] [PubMed]

59. Cullen, J.M. Engineering Fundamentals of Energy Efficiency. Ph.D. Thesis, University of Cambridge, Cambridge, UK, 2009. [CrossRef]

Publisher's Note: MDPI stays neutral with regard to jurisdictional claims in published maps and institutional affiliations.

(C) 2020 by the authors. Licensee MDPI, Basel, Switzerland. This article is an open access article distributed under the terms and conditions of the Creative Commons Attribution (CC BY) license (http:/ / creativecommons.org/licenses/by/4.0/). 